$\# 20260-07-08$

$$
\begin{aligned}
& 66407 \mid \\
& \text { DP-1031 } \\
& \text { oL } 1000-0307-92-202 \\
& N 60-07-08
\end{aligned}
$$

AEC RESEARCH AND DEVELOPMENT REPORT

\title{
INTERACTION OF FISSILE UNITS
}

A Computer Code - INTERACT

H. K. CLARK
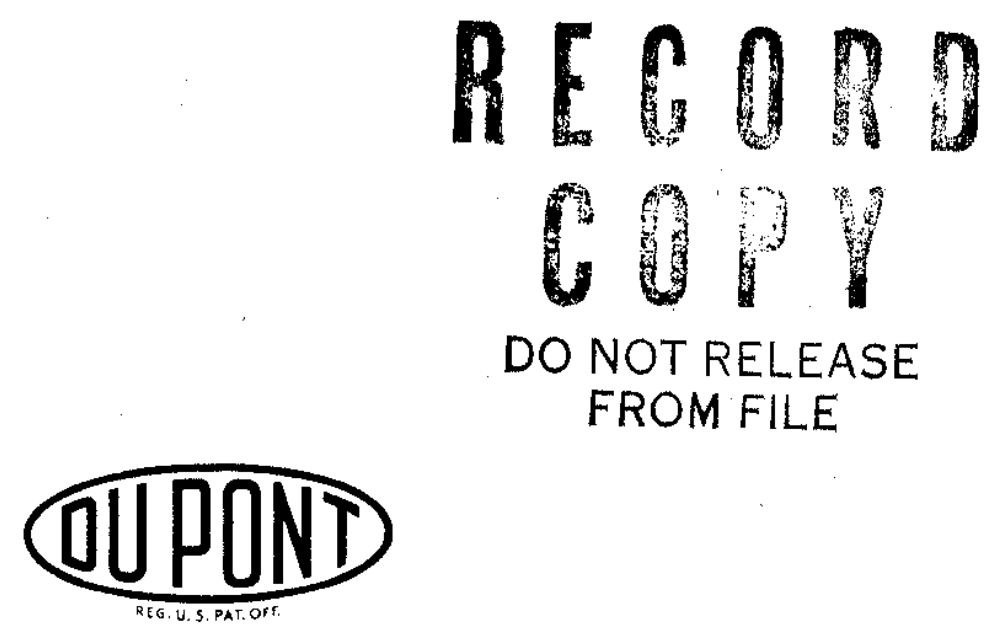

Savannah River Laboratory

Aiken, South Carolina 


\section{LEGAL NOTICE}

This report was prepared as an account of Government sponsored work. Neither the United States, nor the Commission, nor any person acting on behalf of the Commisston:

A. Makes any warranty or representation, expressed or implied, with respect to the accuracy, completeness, or usefulness of the information contained in this report, or that the use of any information, apparatus, method, or process disclosed in this report may not infringe privately owned rights; or

B. Assumes any liabllities with respect to the use of, or for damages resulting from the use of any information, apparatus, method, or process disclosed in this report.

As used in the above, "person acting on behalf of the Commission" includes any employee or contractor of the Commission, or employee of such contractor, to the extent that such employee or contractor of the Commission, or employee of such contractor prepares, disseminates, or provides access to, any information pursuant to his employment or contract with the Commission, or his employment with such contractor.

Printed in USA. Price $\$ 3.00$

Available from the Clearinghouse for Federal Scientific and Technical Information, National Bureau of Standards,

U. S. Department of Commerce, Springfield, Va. 22151 
DP-1031

Criticality studies

(TID-4500)

\section{INTERACTION OF FISSILE UNITS \\ A Computer Code - INTERACT}

by

Hugh K. Clark

Parts of this work were presented at the Symposium on Criticality Control of Fissile Materials, sponsored by the International Atomic Energy Agency, at Stockholm, Sweden, November 1-5, 1965.

\section{Approved by}

P. L. Roggenkamp, Research Manager Theoretical Physics Division

June 1966

\section{E. I. DU PONT DE NEMOURS \& COMPANY} SAVANNAH RIVER LABORATORY

AIKEN, S. C. 29801

CONTRACT AT(07.2).1 WITH THE

UNITED STATES ATOMIC ENERGY COMMISSION 


\section{ABSTRACT}

A FORTRAN code is described which computes the $k_{e f f}$ for a group of fissile units surrounded by a reflector and the spacing between units required to make $k_{e f f}$ unity. A number of approximations are made to simplify the calculations. Comparisons with experiment, of which many are included, serve to normalize the calculations. The code may be used with confidence for nuclear safety applications. In addition to the dimensions and spacings of units and reflectors, the required input includes the material buckling, the bare extrapolation distance, the migration area of the fissile units, and the albedo of the reflector. 


\section{CONTENTS}

Page

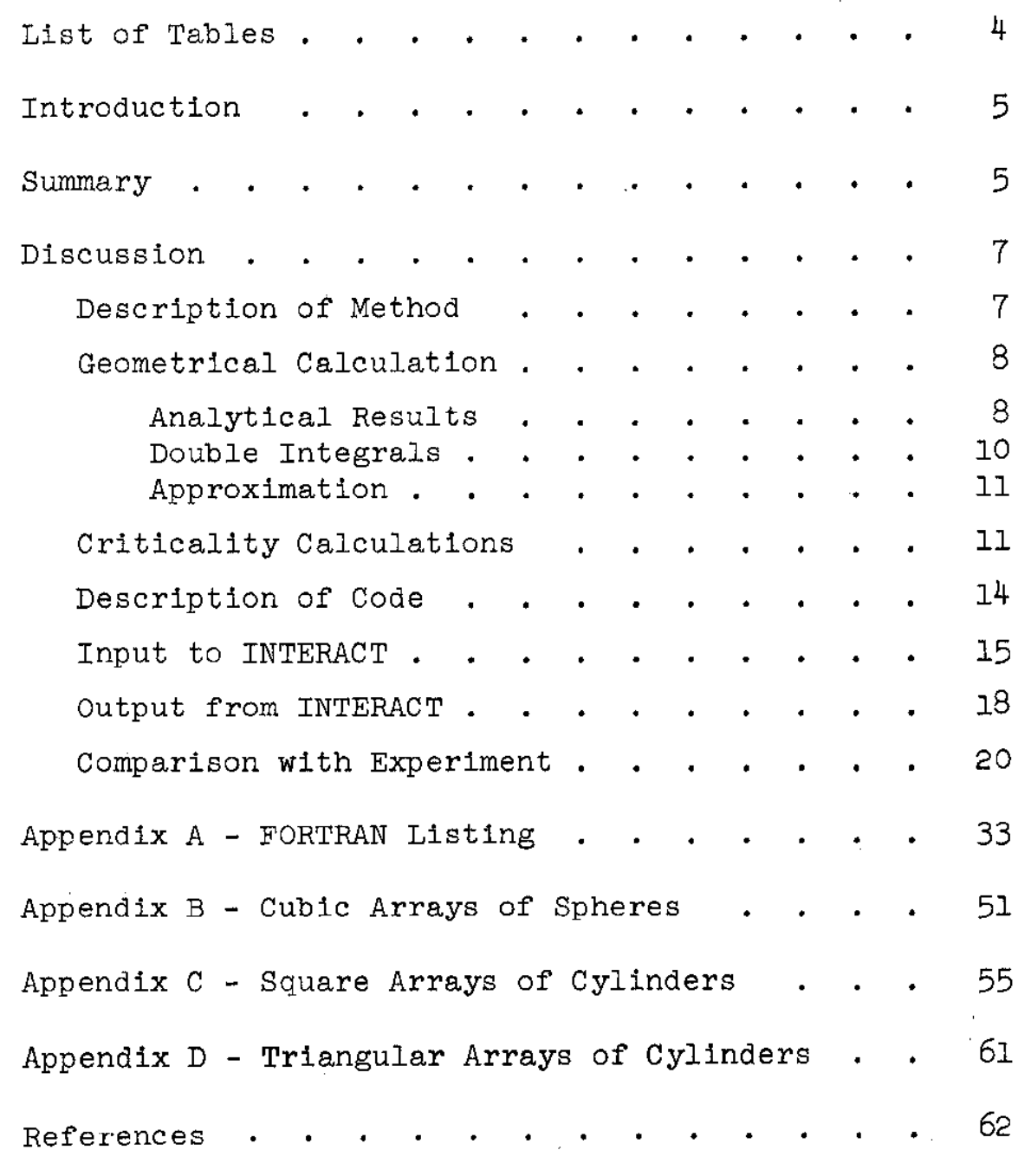




\section{LIST OF TABLES}

Table

Page

I Parallel 15.1- and 7.6-cm-Thick Slabs of Solution Containing $76 \mathrm{~g}^{235} \mathrm{U} / \mathrm{l}$. . . . . . 21

II Parallel 7.6-cm-Thick Slabs of Solution Containing $480 \mathrm{~g}^{235} \mathrm{U} / 1$.

III Perpendicular 15.I- and 7.6-cm-Thick Slabs of Solution Containing $798^{235} \mathrm{U} / 1$. . . . 22

IV Parallel Slabs of Uranium Metal . . . . . . . 23

$\mathrm{V} \quad$ 15.1-cm-Thick Slab of Solution Containing $79 \mathrm{~g}{ }^{235 \mathrm{U} / 1}$ Parallel to a Reflector. . . . . 24

VI Pairs of Cylinders . . . . . . . . . 25

VII Groups of Cylinders of Solution
Containing about $5008^{235} \mathrm{U} / 1 . .$.

VIII Groups of Cylinders of Solution
Containing 84 \& $235 \mathrm{U} / 1$. . . . . . . . . . . . . . 27

IX Groups of 24.1-cm-Diameter Cylinders of Solution Containing $87 \mathrm{~g}^{235} \mathrm{U} / 1$. . . . . . 28

$X$ Groups of 15.24-cm-Diameter Cylinders of Solution Containing $380 \mathrm{~g}^{235} \mathrm{U} / 1$. . . . . . . 29

XI Groups of $24.13-\mathrm{cm}-D$ lameter Cylinders of
Solution Containing about $890 \mathrm{~g} \mathrm{U}(4.9) / 1 . . \quad . \quad . \quad 30$

XII Cylinder (25.4-cm-dia) and Slab (15.I-cm-thick, 120.6-cm-long) of Solution Contalning $78 \mathrm{~g}^{235} \mathrm{U} / \mathrm{I}$. 31 


\section{INTERACTION OF FISSILE UNITS \\ A Computer Code - INTERACT}

\section{INTRODUCTION}

Fissile material encountered in operations performed outside of reactors usually exists as discrete units. In some cases, for example in storage, units may be identical and may be regularly spaced. In other cases, for example in a process line, units may have different sizes, shapes, and compositions and may be irregularly spaced. In all cases, reflectors may be actually or potentially present. A survey of normal and credible abnormal conditions, such as is required to establish the nuclear safety of an operation, therefore generally requires reliable estimates of the interaction within groups of units and reflectors.

Although the general calculation of interaction is a complicated problem, a few reasonable, simplifying approximations can be made that greatly reduce the complexity. Absolute accuracy is not of prime importance since, regardless of the degree of exactness incorporated in a method, its reliability should be established by comparison with experiment. Discrepancies between experiment and calculations can be factored into later calculations as a normalizing parameter.

A simple, practical method for computing interaction was developed several years ago at the Savannah River Laboratory, and has been in use ever since. Many comparisons have been made with experiment. Although computer codes were written to perform the calculations, they were restricted to the geometrical part of the calculations. These codes, which have not previously been described, have now been incorporated in a single over-all code, which performs not only the geometrical part of the calculation, but which also for many cases of interest computes $k_{e f f}$ for a specified group of fissile units and adjusts the spacing between units so as to make keff unity.

\section{SUMMARY}

The INTERACT code for computing keff for groups of fissile units and for computing "critical" spacings corresponding to a $k_{\text {eff }}$ of unity is described; the FORTRAN listing is also given. The basic assumptions in the code are:

- For calculating the probability of transmission from one unit to another, the current transmitted from a surface is assumed to be uniform over the surface and to have an angular distribution per 
unit solid angle proportional to the cosine of the angle between the direction of neutron travel and the normal to the surface.

- For calculating $k_{e f f}$, transmitted and received currents are assumed to have the same surface distributions, the calculation is made one-dimensional, and the same spatial distribution is assumed for neutrons of all energies (one-group approximation).

The code can perform calculations for groups of slabs, cylinders, or spheres. Options are available for several groupings of slabs. The required input consists of dimensions and spacings of units, the reflector albedo, the material buckling, the bare extrapolation distance, and the migration area. The code can be limited solely to the calculation of transmission probabilities, if desired.

The code is satisfactory for use in nuclear safety calculations provided care is taken not to underestimate the reactivity of a unit or the albedo of a reflector. Tables I-XII give numerous comparisons with experimental critical configuraticns, expressed in terms cf the $\mathrm{k}_{\text {eff }} \mathrm{f}^{\prime} \mathrm{s}$ that the experiments are calculated to have. A study of the tables serves to indicate calculated values of $k_{\text {eff }}$ that shculd be considered safely subcritical for situations similar to those included in the tables. Scme gereral cbservaticns may be made as follcws:

- No values of $k_{\text {eff }}<0.9$ have been calculated and only a few $<0.95$.

- The low values occur with small bare groups at close spacings and presumably result chiefly from the nonconservatism of the assumption of uniform current. There is also some indication that the calculated values of keff decrease as the size of units relative to the critical size of a bare critical unit decreases.

- Keff tends to increase with group size, presumably in part because of the conservatism in the manner of allowing for shielding within a group.

- For slabs, keff increases and then decreases as the spacing increases.

- For pairs of cylinders, except in some cases at contact, $\mathrm{k}_{\text {eff }} \cong 1.00$.

- Except at contact the interaction between a $121-\mathrm{cm}-10 \mathrm{ng}$, 15.1-cmthick slab and a 25.4-cm-diameter cylinder, parallel to the slab at its center and having the same height, is calculated quite well. 


\section{DISCUSSION}

\section{Description of Method}

The problem is divided into:

- Purely geometrical calculation of the probabllities of neutron transmission from each unit in a group to each of the other units (including reflectors).

- Calculation of the criticality factor of a unit from a boundary condition expressed in terms of the ratio of the neutrons entering the unit to the neutrons leaving the unit, as determined by these probabilities.

This division of the problem can always be made without introducing any approximation, but it results in a simplification only if approximations are made regarding ( 1 ) distribution of neutron current over transmitting and receiving surfaces, and (2) angular distribution of neutrons transmitted from an element of surface.

Approximations made here for performing the geometrical calculation of probability of transmission from one unit to another are:

- Transmitted current is treated as uniform over the entire surface of a sphere or cylinder and over either of the two principal surfaces of a slab.

- Probability per unit solid angle of neutrons being transmitted from an element of surface at an angle $\theta$ with respect to the normal to the element is $\frac{\cos \theta}{\pi}$.

The reasonableness of these approximations has been discussed elsewhere(I). For a slab and along the length of a cylinder, the assumption of a uniform current tends to compensate for lgnoring the actual skewness of the angular distribution.

Criticality calculations are made in one dimension only, i.e., radial for a sphere or cylinder, or perpendicular to the two principal surfaces for a slab. If a slab is so oriented that neutrons are transmitted to an end as well as to its principal surfaces, the neutrons are treated as though they all enter the principal surfaces; neutrons transmitted from the end to other units are treated as though they were transmittea from the principal surfaces. Separabllity is assumed in slabs and cylinders, and finite transverse dimensions are allowed for by subtracting $\mathrm{B}_{\mathrm{z}}{ }^{2}=\frac{\pi^{2}}{\left(\mathrm{H}+2 \mathrm{~S}_{\mathrm{H}}\right)^{2}}$ and $\mathrm{B}_{\mathrm{g}}{ }^{2}=\frac{\pi^{2}}{\left(\mathrm{~L}+2 \mathrm{~S}_{\mathrm{L}}\right)^{2}}$ from the material 
buckling, where $S_{H}$ and $S_{L}$ are appropriate extrapolation distances. Transmitted and received currents are assumed to have the same surface distributions.

Some care must be exercised in applying these approximations. For closely spaced units, current is clearly greater on portions of surfaces facing each other than elsewhere. Conservative approximations (such as subdividing units) could be introduced to allow for this effect. There are, however, sufficient experimental data now available to permit estimates to be made of its magnitude.

\section{Geometrical Calculation}

On the basis of these approximations, the probability, $\rho_{\mathrm{Jk}}$, that neutrons emitted from a surface, $k$, reach a surface, $j$, is

$$
\rho_{j k}=\int_{A_{j}} \int_{A_{k}} \frac{\cos \theta_{j} \cos \theta_{k} d A_{j} d A_{k}}{\pi R^{2} A_{k}}
$$

where $A_{K}$ is the entire area of transmitting surface and $\frac{d A_{j} \cos \theta_{j}}{R^{2}}$ is the element of solid angle subtended by an element of receiving surface, $\mathrm{dA}_{\mathrm{j}}$, at $\mathrm{dA}_{\mathrm{k}}$. Integration is carried out over the entire transmitting and receiving surfaces. This quadruple integral has been evaluated for a number of cases analytically, and for others has been reduced to a double integral, which can be evaluated numerically by quadrature.

Analytical Results (1)

For two infinitely long parallel rectangular surfaces having height, $h$, and separation, $s$,

$$
\rho=\sqrt{i+(s / h)^{2}}-s / h
$$

For two parallel coaxial discs having transmitter and receiver radil, $a$ and $b$, and separation, $s$,

$$
\rho=\frac{1}{2}\left\{1+(b / a)^{2}+(s / a)^{2}-\sqrt{\left[1-(b / a)^{2}-(s / a)^{2}\right]^{2}+4(s / a)^{2}}\right\}
$$

For two perpendicular rectangular surfaces having transmitter height, $2 a$, and length, $2 h$; having receiver width, $2 d$, and length, 2g; having a separation, $b$, between the lower edge of the transmitter and the plane of the receiver; having a separation, $f$, between the centers of the transmitter and recelver measured in the common direction of $2 \mathrm{~h}$ and $2 \mathrm{~g}$; and having a separation, e, between the profection 


$$
\rho=I+\frac{h}{d}-\sqrt{1+\frac{h^{2}}{d^{2}}}
$$

A similar approach can be used when a reflector surrounds an array. The probability of reaching the reflector is unity minus the sum of the probabilities of reaching other units; the probability of transmission from the reflector to the unit is the product of this probability and the ratio of the area of the unit to that of the reflector.

\section{Double Integrals}

For a pair of spheres having radius, $a$, and center-to-center separation, d, Equation (1) can be reduced(2) to

$$
\rho=\frac{1}{2 \pi} \int_{0}^{1} \int_{x_{1}(y)}^{x_{2}(y)}[v(x, y)+w(x, y)] d x d y
$$

where

$$
\begin{gathered}
v(x, y)=\tan ^{-1} \sqrt{\frac{\left[(y-a / d) \sqrt{1-x^{2}}+x \sqrt{1-y^{2}}\right]^{2}}{1-2 a y / d}-1} \\
w(x, y)=\frac{\sqrt{1-2 a y / d} \sqrt{a^{2}\left(x^{2}+y^{2}\right) / d^{2}-\left[\sqrt{\left(1-x^{2}\right)\left(1-y^{2}\right)}-x(y-a / d)\right]^{2}}}{\left[(y-a / d) \sqrt{1-x^{2}}+x \sqrt{1-y^{2}}\right]^{2}}
\end{gathered}
$$

The lower limit is

$$
x_{1}(y)=\frac{-a(y-a / d) / d+\sqrt{1-y^{2}} \sqrt{1-2 a y / d}}{a^{2} / d^{2}+1-2 a y / d}
$$

When $y \leqslant 2 a / d, x_{2}(y)=1$; when $y>2 a / d$,

$$
x_{2}(y)=\frac{a(y-a / d) / d+\sqrt{1-y^{2}} \sqrt{1-2 a y / d}}{a^{2} / d^{2}+1-2 a y / d}
$$

For a pair of cylinders having height, $h$, radius, $a$, and axisto-axis separation, d

$\rho=\frac{1}{2 \pi^{2}} \int_{-1}^{1} \int_{-1}^{1} \frac{\tan ^{-1}\left[\frac{h / a}{\sqrt{d^{2} / a^{2}-(u+v)^{2}}-\sqrt{1-u^{2}}-\sqrt{1-v^{2}}}\right]}{\sqrt{d^{2} / a^{2}-(u+v)^{2}}} d u d v$ 
of the transmitter on the plane of the receiver and the center of the recelver,

$$
\begin{aligned}
\rho=\frac{1}{8 \pi a h} \sum & {\left[G\left(z, z^{\prime}\right) H\left(x, y^{\prime}\right) \tan ^{-1} \frac{G\left(z, z^{\prime}\right)}{H\left(x, y^{\prime}\right)}\right.} \\
& +\frac{G\left(z, z^{\prime}\right)^{2}}{4} \log \frac{G\left(z, z^{\prime}\right)^{2}+H\left(x, y^{\prime}\right)^{2}}{G\left(z, z^{\prime}\right)^{2}} \\
& \left.-\frac{H\left(x, y^{\prime}\right)^{2}}{4} \log \frac{G\left(z, z^{\prime}\right)^{2}+H\left(x, y^{\prime}\right)^{2}}{H\left(x, y^{\prime}\right)^{2}}\right]
\end{aligned}
$$

where

$$
\begin{aligned}
G\left(z, z^{\prime}\right) & =z+f-z^{\prime} \\
H\left(x, y^{\prime}\right)^{2} & =(x+e)^{2}+\left(y^{\prime}+a+b\right)^{2}
\end{aligned}
$$

Summation (with proper regond to sign) is over the 16 terms resulting from evaluating this quadruple integral at the limits

$$
\begin{aligned}
& -a \text { and } a \text { for } y^{\prime} \\
& -h \text { and } h \text { for } z^{\prime} \\
& -e \text { (or }-d \text { if } e>d \text { ) and } d \text { for } x \\
& -g \text { and } g \text { for } z
\end{aligned}
$$

The probability of neutrons being transmitted from a rectangular surface having helght, $2 a$, and length, $2 h$, to an identical parallel rectangular surface separated from it by a distance, $2 d$, is clearly optained by subtracting from unity twice the sum of the probabilities of reaching perpendicular rectangular surfaces, one having a height, $2 a$, and a width, $2 d$, and the other a width, 2d, and a length, $2 h$. For each case, Equation (4) reduces to only three terms.

Evaluation of Equation ( 1 ) by subtracting from unity the probabilities of neutrons reaching surfaces other than the receiving surface of interest is frequently useful. For example, the probability of transmission from the inner surface of a cylinder to 1 tself is obtained by subtracting from unity twice the probability of reaching the disc capping either end. From the reciprocity inherent in Equation (1), this latter probability is obtalned by subtracting from unity the probability of transmission from one disc to the other and multiplying the result by the ratio of the areas of the disc and cylinder. The resulting self-transmission probabllity for the inner surface of a cylinder of helght, $h$, and diameter, $d$, is 
If the cylinders are infinitely long, the integral can be evaluated analytically, as Carlvik and Pershagen $(\theta)$ show, ylelding

$$
\rho=\frac{I}{\pi}\left[\sin ^{-1} \frac{2 a}{d}-\tan \left(\frac{1}{2} \sin ^{-1} \frac{2 a}{d}\right)\right]
$$

\section{Approximation}

In cases where evaluations of Equation (1) are not ava1lable, various approximations can be made. From symmetry considerations, the probability of transmission from a sphere to another surface must be at least as great as the fraction of $4 \pi$ steradians subtended by the other surface at the center of the sphere and from an infinite cylinder, at least as great as the fraction of $2 \pi$ radians subtended at the axis. Spheres can be approximated by cubes and cylinders by parallelepipeds, and Equation (4) can be used to obtain the transmission probabilities. For pairs of identical cylinders or spheres at small separations, this procedure overestimates $(i)$ the transmission probabilities.

In arrays, nearer neighbors may partially block the path to more distant neighbors. Various schemes can be used to estimate the resulting reduction in transmission probability. The scheme used here is to extend the array conceptually to infinity and to assume no blockage for successively more distant neighbors (except for those completely blocked from view) until the sum of the probabilities totals unity, after which more distant neighbors are assumed to be totally blocked from view. A reduction of the last probability incorporated in the sum is generally required to make the sum exactly unity.

\section{Criticality Calculations}

There is no restriction on the number of neutron energy groups that may be employed with this method. In view of the approximations being made, however, use of many groups can hardly be fustifled. Where reflectors are involved that alter the energy spectrum, there would be some advantage in using at least two groups. In the present treatment a single group is used, i.e., the spatial shape of the flux is assumed to be the same for all energies.

The total current $\mathrm{J}_{1}^{-}$(1.e., the current integrated over the surface) received by each surface, 1 , is given in terms of total transmitted currents, $\mathrm{J}_{j}^{+}$, and transmission probabilities, $p_{1 j}$, by

$$
\mathrm{J}_{1}{ }^{-}=\sum_{j=1}^{\mathrm{N}} \rho_{i j} \mathrm{~J}_{j}^{+} \quad 1=I, N
$$

where $N$ is the number of surfaces involved. (Unless the surface is concave, $\rho_{11}$ is zero.) 
For a unit to be critical the ratio of $\mathrm{J}_{1}^{-}$to $\mathrm{J}_{1}^{+}$must have a definite value depending on the composition and dimensions of the unit. A reasonable approximation ${ }^{(1)}$ is

$$
\frac{J^{-}}{J^{\mp}}=\frac{\phi+\frac{2}{3 \Sigma} \nabla \phi}{\phi-\frac{2}{3 \Sigma} \nabla \phi}
$$

where $\phi$ and $\nabla \phi$ are the flux and its gradient at the surface and $\Sigma$ is the transport cross section. It is convenient to express $\Sigma$ in terms of the bare extrapolation distance, $S_{O}$, by making use of the fact that $\mathrm{J}^{-}=0$ for an isolated surface and to introduce the critical extrapolation distance, $S$, to obtain a symmetrical expression for $\beta_{1}=\mathrm{J}_{1}^{-} / \mathrm{J}_{1}^{+}$, where for a sphere $S=\pi / B_{r}-R$, for a cylinder $S=2.4048 / B_{r}-R$, and for a slab $S_{1}=\pi / B_{X}-T-S_{2}$ and where $R$ is the critical radius, $T$ the critical slab thickness, and $S_{2}$ the extrapolation distance at the opposite surface. The resulting expressions for slab, cylinder, and sphere are:

$$
\begin{gathered}
\beta_{1}=\frac{\sin B_{x}\left(S_{1}-S_{0}\right)}{\sin B_{x}\left(S_{1}+S_{0}\right)} \\
\beta_{i}=\frac{\frac{J_{0}\left(2.4048-B_{r} S\right)}{J_{1}\left(2.4048-B_{r} S\right)}-\frac{J_{0}\left(2.4048-B_{r} S_{0}\right)}{J_{1}\left(2.4048-B_{r} S_{0}\right)}}{\frac{J_{0}\left(2.4048-B_{r} S\right)}{J_{1}\left(2.4048-B_{r} S\right)}+\frac{J_{0}\left(2.4048-B_{r} S_{0}\right)}{J_{1}\left(2.4048-B_{r} S_{0}\right)}} \\
\beta_{1}=\frac{\pi-B_{r} S}{\frac{\pi-B_{r} S_{0}}{I+\left(\pi-B_{r} S\right) \cot B_{r} S}-\frac{\pi}{I+\left(\pi-B_{r} S_{0}\right) \cot B_{r} S_{0}}}
\end{gathered}
$$

For a slab, the $\beta_{i}$ at its two surfaces are necessarily related so that if $\beta_{1}$ is specified $\beta_{2}$ is given by

$$
\beta_{2}=\frac{\sin 2 B_{X}\left(\bar{S}-S_{0}\right)-\beta_{1} \sin 2 B_{X} \bar{S}}{\sin 2 B_{X} \bar{S}-\beta_{I} \sin 2 B_{X}\left(\bar{S}+S_{0}\right)}
$$

where $2 \vec{S}=\frac{\pi}{B_{X}}-\mathrm{T}$. 
With the introduction of $\beta_{i}$, Equations (9) become

$$
\sum_{j=1}^{N}\left(\beta_{i} \delta_{i j}-\rho_{i j}\right) J_{j}^{+}=0 \quad i=1, N
$$

which are homogeneous in the $\mathrm{J}_{1}^{+}$; hence a solution is obtained by finding the appropriate values of $\beta_{1}$ that make the determinant of the coefficients of the $\mathrm{J}_{1}^{+}$zero. When identical units occupy symmetrically equivalent positions, their $\mathrm{J}_{1}{ }^{+}$are all equal, as are their $\mathrm{J}_{1}{ }^{-}$; hence the number of equations can be reduced to the number of symmetrically different positions. If all units are different, the $\beta_{i}$ for all units except one can be evaluated from their compositions and sizes by Equation (1I) and the value that $\beta$ for this unit must have in order that the group be critical is determined from the requirement that the determinant be zero. For a group of 1dentical spheres, cylinders, or slabs treated as though they are symmetrical by setting $\beta_{1}=\beta_{2}=\frac{\sin B_{X}\left(\bar{S}-S_{0}\right)}{\sin B_{X}\left(\bar{S}+S_{0}\right)}$, the $\beta_{1}$ are all the same; $\beta_{1}$ is then the maximum elgenvalue of the matrix of coefficients.

By definition, $\beta_{1}$ is the albedo that the medium surrounding a surface must have if the unit is to be critical and $\alpha_{1}=\beta_{1}^{-1}$ is the albedo of the surface as determined by the size and composition of the unit. For reflectors, the appropriate albedo may be difficult to calculate. If, however, the extrapolation distance is known when the reflector is in contact with a unit, the albedo of the reflector can be obtained from the relation

$$
\alpha_{r}=\beta_{u}
$$

Although the extrapolation distance is insensitive to the radius of curvature of the reflector, the albedo is not; and corrections for changes in curvature should be made. Where a reflector surrounds an array, it is simplest to assume a flat surface and to use Equations (11a) and (14) to determine its albedo.

In general, $\beta$ as obtained by Equation (13) will not equal $\beta$ as calculated by Equation (II) from the size and composition of the unit, 1.e.g $S$ as obtained from Equations (II) and (13) will not be consistent with the actual size of the unit. It is convenient to calculate a geometric buckling from this $S$ and the actual dimensions and to calculate $\mathrm{k}_{\text {eff }}$ as

$$
k_{\text {eff }}=\frac{I+M^{2} B_{m}^{2}}{I+M^{2} B_{g}^{2}}
$$


where $\mathrm{B}_{\mathrm{m}}^{2}$ is the materlal buckling and $\mathrm{M}^{2}$ is an appropriate migration area.

By comparing the $k_{\text {eff }}$ so calculated for a unit within a group with values calculated for units in similar groups found experimentaliy to be critical, a judgment can be made as to whether the group would be subcritical. Dimensions, spacings, and compositions can be adjusted until $\mathrm{k}_{\text {eff }}$ has the desired value.

\section{Description of Code}

The INTERACT code Iisting is given in Appendix A. The main program serves to exercise input and output options and to call the appropriate subroutine. It has three principal subroutines: SLAB, CLNDR, and SPHERE. As the names imply, calculations for groups of slabs, cylinders, or spheres are made in these subroutines.

In SLAB there are options for twelve different groupings of slabs; a thirteenth option simply evaluates Equation (4) for a general case. other groupings of slabs can easily be added with additional coding. Evaluations of Equation (4) are performed in Subroutine NTRCT. Modifications in the initial spacing to make $k_{\text {eff }}$ unity are made with Subroutine SEP.

CLNDR performs calculations for a group of identical cylinders, which may or may not be surrounded by a reflector. The evaluations of Equation (7) are performed in CIDRCT by 16-point Gaussian quadrature or, where appropriate, by Equation (8). The maximum elgenvalue of the matrix of coefficients of the currents transmitted from the cylinders is calculated by Subroutine MAX. Subroutine SEP is used in modifying the initial spacings so as to make $k_{\text {eff }}$ unity. A Bessel function subroutine is required for $k_{\text {eff }}$ calculations.

SPHERE performs calculations for a group of identical spheres, which may or may not be surrounded by a reflector. The evaluations of Equation (6) are performed in SPHRCT by ll-point Lagrange interpolation of the amounts by which the ratios of Gaussian quadratures of Equation (6) to the corresponding solid angles subtended by one sphere at the center of another exceed unity. This approach is taken because many evaluations of the integral may be required and double 16-point Gaussian quadrature (256 evaluations of the integrand) consumes too much machine time. The maximum eigenvalue and adjustments in the initial spacing are obtained with MAX and SEP. 


\section{Input to INTERACT}

As many cards are used as are required by the information being supplied. Each card is begun at the left. Cards that apply only to certain types of problems should be omitted for other types. The cards must be read onto an input data tape (Tape 5). The code is designed to be run on a monitor system on the IBM 704 .

Format

Data

$14 I 5$

$I C(I), I=1,5$

IC (1) denotes unit type

IC $(1)=1$ denotes a group of slabs

IC $(1)=2$ denotes a group of cylinders

$I C(1)=3$ denotes a group of spheres

If $I C(1)=0$, the program calls EXIT

IC(2) describes type of problem

For IC $(1)=1$, IC $(2)=1$ denotes two bare, parallel, identical slabs

IC $(2)=2$ denotes two bare, parallel, slabs, one twice as thick as the other

IC $(2)=3$ denotes three bare, parallel, identical slabs

IC $(2)=4$ denotes two bare, perpendicular Identical slabs in I configuration

IC $(2)=5$ denotes two bare, perpendicular slabs, one twice as thick as the other in I configuration

IC $(2)=6$ denotes two bare, perpendicular identical slabs in $T$ configuration

IC (2) $=7$ denotes two bare, perpendicular slabs, one twice as thick as the other, in $T$ configuration

IC $(2)=8$ denotes three bare, parallel slabs, center slab twice as thick as the others

$I C(2)=9$ denotes two bare, parallel, identical discs 


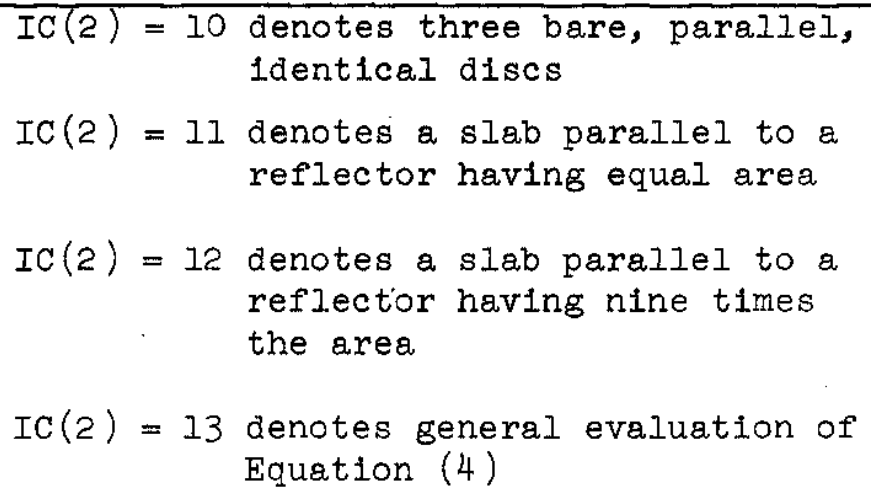

For IC $(1)=2, \operatorname{IC}(2)=0$ denotes an array of cylinders

For $I C(1)=3, \operatorname{IC}(2)=0$ denotes an array of spheres $I C(2)=1$ denotes an array of cylinders to be treated as spheres

IC (3) denotes number of comment cards (maximum of 9)

IC (4) denotes number of axis-to-axis or center-to-center spacings, expressed as squares of multiples of the minimum spacing, to be read for arrays of cylinders or spheres. If $\mathrm{IC}(4)=0$, the spacings from the previous problem are used.

IC (5) denotes format to be used for reading WUF. If $\mathrm{IC}(5)=0$, format is 6F2.0, 60FI.0; otherwise $1 \mathrm{t}$ is $24 \mathrm{~F} 3.2$

12A6 Problem description or other comments. The number of cards to be read is IC (3)

$14 F 5.0(\operatorname{SDU}(I), I=1, I C(4)),(\operatorname{WDI}(I), I=1, I C(4))$

Applies only for cylinders and spheres. SDU denotes squares of the ratios of axis-to-axis or center-to-center spacings between units to the minimum spacing arranged in increasing order. WDI denotes the number of units at each spacing in an infinite lattice formed by extending the lattice under consideration.

8F5.2, DH, DL, SP, DW, AR, SO, SH, SL, B, AM

$2 \mathrm{~F} 20.5$

Applies only for slabs. For IC (2) < 13, DH = slab helght, $\mathrm{DL}=\mathrm{slab}$ length, $\mathrm{SP}=$ surface-to-surface separation, 
$D W=$ slab thickness, $A R=$ reflector albedo, $S O=$ bare extrapolation distance, $\mathrm{SH}$ and $\mathrm{SL}=$ extrapolation distances on height and length, $\mathrm{B}=$ material buckling, and $\mathrm{AM}=$ migration area. For IC $(2)=13, \mathrm{DH}=$ transmitter height, $\mathrm{DL}=$ transmitter length, $S P=$ recelver wlath, $D W=$ separation between lower edge of transmitter and plane of recelver, $A R=$ length of receiver, SO = separation between centers of transmitter and recelver measured in the common direction of their length, and $\mathrm{SH}=$ separation between projection of transmitter on plane of receiver and center of receiver. If $\mathrm{DH}=0$, IC card is read next.

2I5, NN, NX, DIA, HU, SR, SP, AR, SO, SH, B, AM

7F5.2, Applies only for cylinders. NN is number of symmetrically $2 \mathrm{~F} 10.5$ different positions, NX is number of units in group, DIA is diameter, HU is height (if height is infinite, $H U=0$ ), $\mathrm{SR}$ is surface area of any surrounding reflector, $\mathrm{SP}$ is minimum axis-to-axis spacing, AR is reflector albedo, so is bare extrapolation distance, $\mathrm{SH}$ is axial extrapolation distance, $B$ is material buckling, $A M$ is migration area. If $N N=0$, IC card is read next.

2I5, NN, NX, DIA, SP, SR, AR, SO, B, AM

$3 \mathrm{~F} 10.5$, 2F5.2, $2 \mathrm{~F} 10.6$

Applies only for spheres. NN is number of symmetrically different positions, $\mathrm{NX}$ is number of units in group, DIA is diameter, SP is minimum center-to-center spacing, SR is surface area of any surrounding reflector, AR is reflector albedo, SO is bare extrapolation distance, B is material buckling, $A M$ is migration area. If $N N=0$, IC card is read next.

2I5, NN, NX, DIA, HU, VOL, TH, STS, AR, SO, B, AM

$7 F 5.2$, Applies only for cylinders to be treated as spheres. NN is $2 F 10.5$ number of symmetrically different positions. NX is number of units in group, DIA and HU are external diameter and height of cylinder, VOL is internal volume, $T H$ is wall thickness, STS is surface-to-surface separation, AR is reflector albedo, So is bare extrapolation distance, $B$ is material buckling, $\mathrm{AM}$ is migration area. If $\mathrm{NN}=0$, IC card is read next.

$14 F 5.0 \quad(W S T(I), I=I, N N)$

Applies only for cylinders and spheres and only if NX differs from its value in the previous problem. WST is number of units in each of NN symmetrically different positions. 
$(\mathrm{WUF}(I, J, K), I=1, I C(4))$

6OFl.0,

or $24 F 3.2$

(Depends

on

Applies only for cylinders and spheres and only if NX differs from its value in the previous problem. WUF is the number of units in position $\mathrm{K}$ transmitting to units in symmetrically equivalent positions $J$ separated from $K$ by spacing $I$. There $\operatorname{IC}(5))$ are NN $x$ NN cards in the deck to be read.

For each $K$, starting with 1 , J runs from 1 through NN. Appendices $B, C$, and D list values of WUF for several arrays of spheres and cylinders.

All dimensions are in $\mathrm{cm}$, buckling is in $\mathrm{cm}^{-2}$, and migration area in $\mathrm{cm}^{2}$. If $\mathrm{B}=0$, only the geometrical calculation is performed; and parameters not needed ( $D W$, SO, SH, SL, B, AM) may be left blank. Following a problem, the next card read is either an IC card as indicated above or a card for another problem of the same type.

\section{Outpuł from INTERACT}

The output consists first of the code title followed by any comments that may have been read in. Next is a statement of the type of problem being run.

For slabs for which IC $(2)<13$ the dimensions are listed, the initial and critical separations, four transmission probabilities corresponding to the critical separation, the materlal buckling, the migration area, the bare extrapolation distance, the critical extrapolation distance (average value for two principal surfaces; refers to larger slab when thicknesses differ), the extrapolation distance corresponding to the critical separation (should equal the critical extrapolation distance if problem converged), reflector albedo, and $k_{\text {eff }}$ corresponding to initial separation.

For IC $(2)=I, 2,3,8$, the first transmission probability is for transmission from one parallel slab to another, the next two are for transmission to the perpendicular rectangles enclosing the space between the slabs, and the fourth is zero. For IC (2) $=9,10$, the first probability is for transmission from one disc to another, and the others are zero. For IC $(2)=4$, 5, the first probability is for transmission from the slab having two surfaces involved to the other slab (having only a princlpal surface involved) as though all neutrons were transmitted from the larger (perpendicular) surface, the second probability is for transmission from the larger surface only, the third probability is for transmission from the smaller (parallel) surface treated as though the neutrons came from the larger surface, 
and the fourth probability is zero. For IC $(2)=6,7$, the first probability is $\sqrt{2}$ times the sum of the next two and represents the square root of the product of the $\beta$ 's for the principal surfaces of the two slabs involved in the interaction; the second probability is for transmission from elther large (perpendicular) surface of the slab having three surfaces involved to the other slab (having only a principal surface involved); the third is one-half the probability for transmission from the small (parallel) surface treated as though the neutrons came from a large surface, and the fourth probability is zero. For IC (2) $=11$, the first probability is for transmission from the slab to the reflector and back; the second probability is for transmission from the slab to the reflector, and the third and fourth are for transmission to the perpendicular rectangles enclosing the space between the slab and the reflector. For $I C(2)=12$, the first probability is for transmission from the slab to the reflector and back, the next two are for transmission to a reflecting slab off-set by the slab helght and by the slab length, and the fourth is for transmission to a reflecting slab off-set by both the height and the length.

For slabs for which $\mathrm{IC}(2)=13$, the output consists of transmitter length, transmitter height, receiver length, receiver width, separation between lower edge of transmitter and plane of recelver, separation between projection of transmitter on plane of receiver and center of receiver, separation between centers of transmitter and receiver measured in common direction of their lengths, and the transmission probability.

For cylinders the output consists of the number of cylinders, the ratio of height to diameter, the initial ratio of diameter to minimum axis-to-axis spacing, the final ratio (critical ratio if problem converged), the ratio of the area of the reflector to the area of the curved surface of a cylinder, the reflector albedo, the final eigenvalue for the group, the material buckling, the migration area, the bare extrapolation distance, the critical extrapolation distance, the final extrapolation distance, and $k_{\text {eff }}$ for the initial spacing.

For spheres (or for cylinders treated as spheres) the output consists of the number of units, the initial and final (critical if converged) ratios of diameter to minimum center-to-center spacing, the ratio of the area of the reflector to that of a sphere, the reflector albedo, the final eigenvalue for the group, the material buckling, the migration area, the bare, critical, and final extrapolation distances, and $k_{\text {eff }}$ for the initial spacing.

If the buckling is zero so that only the geometrical part of the calculation is performed, all unused parameters are left blank. 


\section{Comparison with Experiment}

A large number of critical experiments have been performed with groups of interacting units and most of the data have been compiled in a recent publication (4). Comparison is made here (Tables I-XII) in terms of calculated and experimental critical separations (taken in some cases from the original reference rather than from the compilation) and in terms of $\mathrm{k}_{\mathrm{eff}}$ calculated for the experimentally critical group. The value of $k_{\text {eff }}$ is somewhat dependent on the value of $\mathrm{M}^{2}$ used. A different migration area, $M^{12}$, would give a different $k^{i}$ eff,

$$
k_{\text {eff }}^{\prime}=\frac{1+\frac{\left(k_{e f f}-1\right) M^{12} B_{m}^{2}}{k_{e f f}+M^{12} B_{m}^{2}}}{1-\frac{\left(k_{\left.e f f^{-1}\right) M^{12}}\right.}{\left(k_{e f f}+M^{12} B_{m}{ }^{2}\right) M^{2}}}
$$

but for $k_{e f f}$ near unity the dependence on $\mathrm{M}^{2}$ is small.

Calculations are of course dependent on the reactivities assumed for individual units. A careful attempt was made to choose $\mathrm{B}_{\mathrm{m}}{ }^{2}$ and $S_{0}$ consistent with experiments performed with bare isolated units so that most of the discrepancy between calculation and experiment results from the method of calculating interaction. The choice is not a unique one, however. Once $S_{0}$ is selected, $B_{m}{ }^{2}$ is determined; but varlous $S_{0}$ may be chosen. One would hope to choose $S_{0}$ such that $\mathrm{B}_{\mathrm{m}}{ }^{2}$ would be independent of shape, but this is probably an impossible goal. The dependence on $S_{O}$ is fairly small, however, as can be seen from Tables $I$ and $X$. A larger value of $S_{O}$ tends to give greater

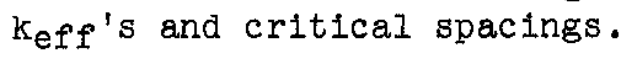

In calculations for solutions the actual separations between solutions were used and vessel walls were ignored (i.e., treated as vacuum). Groups involving thick and thin slabs were assumed to contain slabs of a particular thickness and slabs of exactly half this thickness. No comparisons of calculations and experiments with three dimensional arrays of units are included since such comparisons have recentiy been published $(2,3)$. The cylinders of solution in Table $X$ were all assumed to have diameters of $15.24 \mathrm{~cm}$ although in the experiments this was the outer dlameter of some of the containers. In the calculations for the interaction between a slab and a cylinder (Table XII), the cylinder was treated as a square cylinder having the same volume in computing the probability of transmission to the slab; this probability was multiplied by the ratio of the actual slab and cylinder areas in computing the probability of transmission from slab to cylinder. 


\section{TABLE I}

Parallel 15.1- and 7.6-cm-Thick Slabs of Solution Containing. $76 \mathrm{~g}{ }^{235} \mathrm{U} / \mathrm{I}(4)$

$$
\mathrm{B}_{\mathrm{m}}^{2}=0.023306 \mathrm{~cm}^{-2}, \mathrm{M}^{2}=32 \mathrm{~cm}^{2}, \mathrm{~S}_{\mathrm{O}}=3.0 \mathrm{~cm}
$$

\begin{tabular}{|c|c|c|c|c|}
\hline \multirow[b]{2}{*}{ Configuration } & \multirow[b]{2}{*}{$\mathrm{Ht}, \mathrm{cm}$} & \multicolumn{2}{|c|}{ Separation, $\mathrm{cm}$} & \multirow[b]{2}{*}{$k_{e f f}$} \\
\hline & & Exptl. & $\mathrm{Calc}$ & \\
\hline $1-\frac{1}{2}$ & $\begin{array}{r}24.9 \\
32.4 \\
44.6 \\
45.0 \\
58.2 \\
58.6 \\
59.7 \\
65.8 \\
68.3 \\
83.1 \\
86.7 \\
92.5 \\
93.5 \\
113.8\end{array}$ & $\begin{array}{r}0.6 \\
5.7 \\
15.9 \\
15.9 \\
31.1 \\
31.1 \\
31.1 \\
38.7 \\
46.4 \\
76.8 \\
76.8 \\
76.8 \\
76.8 \\
107.3\end{array}$ & $\begin{array}{r}0.4 \\
7.1 \\
20.9 \\
21.4 \\
39.3 \\
39.8 \\
41.5 \\
50.7 \\
55.0 \\
81.5 \\
88.6 \\
99.8 \\
101.9 \\
163.2\end{array}$ & $\begin{array}{l}0.997 \\
1.010 \\
1.017 \\
1.019 \\
1.013 \\
1.014 \\
1.016 \\
1.014 \\
1.008 \\
1.002 \\
1.004 \\
1.008 \\
1.008 \\
1.007\end{array}$ \\
\hline$\frac{1}{2}-1-\frac{1}{2}$ & $\begin{array}{l}19.6 \\
44.2 \\
62.5 \\
81.5\end{array}$ & $\begin{array}{r}0.6 \\
26.0 \\
51.4 \\
81.9\end{array}$ & $\begin{array}{r}0.1 \\
32.4 \\
63.9 \\
102.1\end{array}$ & $\begin{array}{l}0.994 \\
1.019 \\
1.015 \\
1.010\end{array}$ \\
\hline $1-1$ & $\begin{array}{l}25.4 \\
32.8 \\
44.9 \\
50.3 \\
59.7 \\
73.2 \\
82.1\end{array}$ & $\begin{array}{r}5.7 \\
15.9 \\
38.7 \\
51.4 \\
76.8 \\
122.6 \\
168.3\end{array}$ & $\begin{array}{c}8.0(8.2)^{(a)} \\
21.5(21.3) \\
51.4(50.7) \\
67.5(66.5) \\
99.6(98.1) \\
155.5(151.8) \\
201.9(201.9)\end{array}$ & $\begin{array}{l}1.016(1.021)^{(a)} \\
1.023(1.024) \\
1.020(1.020) \\
1.018(1.017) \\
1.014(1.013) \\
1.009(1.008) \\
1.005(1.005)\end{array}$ \\
\hline$\frac{1}{2}-\frac{1}{2}-\frac{1}{2}$ & $\begin{array}{r}25.5 \\
34.4 \\
58.8 \\
85.5 \\
107.4 \\
120.4\end{array}$ & $\begin{array}{r}0.6 \\
3.2 \\
8.3 \\
12.1 \\
14.6 \\
15.9\end{array}$ & $\begin{array}{c}0.5(0.8)^{(a)} \\
3.8(3.8) \\
10.6(9.9) \\
15.7(14.4) \\
18.8(17.1) \\
20.3(18.4)\end{array}$ & $\begin{array}{l}0.998(1.001)^{(a)} \\
1.006(1.007) \\
1.016(1.014) \\
1.020(1.015) \\
1.020(1.015) \\
1.020(1.014)\end{array}$ \\
\hline
\end{tabular}

(a) Values in parentheses calculated with $S_{0}=2.5 \mathrm{~cm}$, $\mathrm{B}_{\mathrm{m}}{ }^{2}=0.025585 \mathrm{~cm}^{-2}$ 


\section{TABLE II}

Parallel 7.6-cm-Thick Slabs of Solution Containing $480 \mathrm{~g}^{235} \mathrm{U} / \mathrm{I}^{(4)}$

\begin{tabular}{|c|c|c|c|c|}
\hline Configuration & $\mathrm{Ht}, \mathrm{cm}$ & $\begin{array}{l}\text { Separa } \\
\text { ExptI. }\end{array}$ & $\frac{\text { on, } \mathrm{cm}}{\text { Calc. }}$ & $\mathrm{k}_{\mathrm{eff}}$ \\
\hline$\frac{1}{2}-\frac{1}{2}$ & $\begin{array}{r}33.4 \\
44.5 \\
59.4 \\
\sim 67.0\end{array}$ & $\begin{array}{l}0.9 \\
3.2 \\
5.7 \\
7.0\end{array}$ & $\begin{array}{l}0 \\
2.3 \\
4.8 \\
5.8\end{array}$ & $\begin{array}{l}0.988 \\
0.992 \\
0.993 \\
0.992\end{array}$ \\
\hline
\end{tabular}

\section{TABLE III}

Perpendicular 15.1- and 7.6-cm-Thick Slabs of Solution Containing $79 \mathrm{~g}^{235 \mathrm{U} / \mathrm{I}}$ (4)

$\mathrm{B}_{\mathrm{m}}^{2}=0.023438 \mathrm{~cm}^{-2}, \mathrm{M}^{2}=32 \mathrm{~cm}^{2}, \mathrm{~S}_{0}=3.0 \mathrm{~cm}$

\begin{tabular}{|c|c|c|c|c|}
\hline \multirow[b]{2}{*}{ Configuration } & \multicolumn{3}{|c|}{ Separation, cm } & \multirow{2}{*}{$k_{e f f}$} \\
\hline & $\mathrm{it}, \mathrm{cm}$ & Exptl. & Calc. & \\
\hline $1-1(\mathrm{~T})$ & $\begin{array}{l}45.2 \\
53.8 \\
67.4 \\
82.8 \\
84.1 \\
87.8\end{array}$ & $\begin{array}{r}3.4 \\
9.1 \\
24.4 \\
47.2 \\
52.3 \\
62.5\end{array}$ & $\begin{array}{r}4.9 \\
20.1 \\
48.6 \\
89.7 \\
94.3 \\
107.8\end{array}$ & $\begin{array}{l}1.003 \\
1.015 \\
1.017 \\
1.014 \\
1.013 \\
1.010\end{array}$ \\
\hline$\frac{1}{2}-1(\mathrm{~T})$ & $\begin{array}{r}79.3 \\
94.9 \\
105.7\end{array}$ & $\begin{array}{r}9.1 \\
24.4 \\
47.2\end{array}$ & $\begin{array}{r}6.0 \\
24.4 \\
47.2\end{array}$ & $\begin{array}{l}0.998 \\
1.000 \\
1.000\end{array}$ \\
\hline $1-1$ (L) & $\begin{array}{l}56.9 \\
71.3 \\
76.6 \\
79.6 \\
84.6 \\
88.9\end{array}$ & $\begin{array}{r}1.5 \\
16.8 \\
29.5 \\
37.1 \\
57.4 \\
77.7\end{array}$ & $\begin{array}{r}25.7 \\
90.0 \\
129.6 \\
168.7 \\
285.3 \\
-\end{array}$ & $\begin{array}{l}1.020 \\
1.026 \\
1.023 \\
1.022 \\
1.018 \\
1.015\end{array}$ \\
\hline$\frac{1}{2}-1(\mathrm{I})$ & $\begin{array}{r}97.5 \\
102.2\end{array}$ & $\begin{array}{r}1.5 \\
16.8\end{array}$ & $\begin{array}{l}28.3 \\
40.8\end{array}$ & 1.0 \\
\hline
\end{tabular}




\section{TABLE IV}

Parallel Slabs of Uranium Metal (4)

$\mathrm{B}_{\mathrm{m}}^{2}=0.08258, \mathrm{M}^{2}=15.7, \mathrm{~S}_{\mathrm{O}}=2.1 \mathrm{~cm}$

\begin{tabular}{|c|c|c|c|c|}
\hline \multirow{2}{*}{\multicolumn{2}{|c|}{$\begin{array}{c}\text { Surface } \\
\text { Dimensions, cm Thlckness, cm }\end{array}$}} & \multicolumn{2}{|c|}{ Separation, cm } & \multirow[b]{2}{*}{$k_{\text {eff }}$} \\
\hline & & ExptI. & Calc. & \\
\hline $\begin{array}{l}20.3 \times 25.4 \\
\text { (Two slabs) }\end{array}$ & $\begin{array}{l}4.76 \\
5.08 \\
5.40 \\
5.71 \\
6.03 \\
6.67 \\
6.98 \\
7.30 \\
7.62 \\
7.94\end{array}$ & $\begin{array}{r}0.3 \\
1.0 \\
1.6 \\
2.4 \\
3.2 \\
5.2 \\
6.4 \\
8.0 \\
9.9 \\
12.5\end{array}$ & $\begin{array}{r}0.5 \\
1.4 \\
2.4 \\
3.4 \\
4.6 \\
7.2 \\
8.8 \\
10.6 \\
12.8 \\
15.7\end{array}$ & $\begin{array}{l}1.003 \\
1.008 \\
1.014 \\
1.018 \\
1.022 \\
1.026 \\
1.027 \\
1.026 \\
1.024 \\
1.020\end{array}$ \\
\hline $\begin{array}{l}38.1 \text { (dia) } \\
\text { (Two slabs) }\end{array}$ & $\begin{array}{l}4.15 \\
4.46 \\
4.77 \\
5.08 \\
5.38 \\
5.72 \\
6.00 \\
6.34\end{array}$ & $\begin{array}{r}1.2 \\
2.5 \\
3.9 \\
5.6 \\
7.4 \\
9.6 \\
12.3 \\
15.7\end{array}$ & $\begin{array}{r}1.9 \\
3.8 \\
5.9 \\
8.0 \\
10.5 \\
13.5 \\
16.3 \\
20.6\end{array}$ & $\begin{array}{l}1.009 \\
1.017 \\
1.023 \\
1.028 \\
1.032 \\
1.035 \\
1.032 \\
1.031\end{array}$ \\
\hline $\begin{array}{l}27.94 \text { (d1a) } \\
\text { (Two slabs) }\end{array}$ & $\begin{array}{l}4.46 \\
4.77 \\
5.08 \\
5.38 \\
5.74 \\
6.00 \\
6.34 \\
6.69 \\
7.00 \\
7.31\end{array}$ & $\begin{array}{r}0.3 \\
1.2 \\
1.9 \\
2.9 \\
3.9 \\
5.1 \\
6.5 \\
8.2 \\
10.2 \\
12.9\end{array}$ & $\begin{array}{r}0.6 \\
1.8 \\
3.1 \\
4.3 \\
5.9 \\
7.2 \\
9.1 \\
11.3 \\
13.7 \\
16.7\end{array}$ & $\begin{array}{l}1.005 \\
1.011 \\
1.018 \\
1.022 \\
1.029 \\
1.028 \\
1.031 \\
1.032 \\
1.030 \\
1.025\end{array}$ \\
\hline $\begin{array}{l}17.78 \text { (d1a) } \\
\text { (Two slabs) }\end{array}$ & $\begin{array}{l}6.69 \\
6.95 \\
7.31 \\
7.61 \\
7.92 \\
8.28\end{array}$ & $\begin{array}{l}0.3 \\
0.6 \\
0.9 \\
1.2 \\
1.5 \\
1.9\end{array}$ & $\begin{array}{l}0.5 \\
0.9 \\
1.4 \\
1.8 \\
2.2 \\
2.8\end{array}$ & $\begin{array}{l}1.004 \\
1.005 \\
1.010 \\
1.012 \\
1.013 \\
1.016\end{array}$ \\
\hline $\begin{array}{l}38.1 \text { (d1a) } \\
\text { (Three slabs) }\end{array}$ & $\begin{array}{l}3.17 \\
3.81 \\
4.44 \\
4.75 \\
5.08\end{array}$ & $\begin{array}{r}2.2 \\
4.5 \\
7.2 \\
8.8 \\
10.7\end{array}$ & $\begin{array}{r}3.3 \\
6.6 \\
10.3 \\
12.3 \\
14.6\end{array}$ & $\begin{array}{l}1.017 \\
1.032 \\
1.042 \\
1.043 \\
1.045\end{array}$ \\
\hline
\end{tabular}




\section{TABLE V}

15.1-cm-Thick Slab of Solution Containing $79 \mathrm{~g}^{235} \mathrm{U} / 1$ Parallel to a Reflector $(5,8)$

\begin{tabular}{|c|c|c|c|c|c|c|}
\hline $\begin{array}{c}\text { Reflector } \\
\text { Albedo }\end{array}$ & $\mathrm{Ht}, \mathrm{cm}$ & ExptI. & $\frac{\text { Separation }}{\text { Calc. }(1)^{(a)}}$ & $\mathrm{cm}$ & $k_{e f f}(1)^{(a)}$ & $k_{e f f}(9)^{(b)}$ \\
\hline $\begin{array}{l}0.475 \\
\text { (concrete) }\end{array}$ & $\begin{array}{r}32.3 \\
47.8 \\
69.6 \\
80.3 \\
92.2 \\
107.2\end{array}$ & $\begin{array}{c}0 . \\
15.2 \\
45.7 \\
68.6 \\
106.7 \\
228.6\end{array}$ & $\begin{array}{c}0 \\
13.2 \\
40.5 \\
58.7 \\
83.5 \\
-\end{array}$ & $\begin{array}{c}0 \\
14.1 \\
47.6 \\
72.8 \\
114.3 \\
228.6\end{array}$ & $\begin{array}{l}1.000 \\
0.995 \\
0.997 \\
0.997 \\
0.997 \\
0.999\end{array}$ & $\begin{array}{l}1.000 \\
0.997 \\
1.001 \\
1.001 \\
1.001 \\
1.000\end{array}$ \\
\hline $\begin{array}{l}0.154 \\
(1.27 \mathrm{~cm} \\
\text { thick steel) }\end{array}$ & $\begin{array}{l}55.3 \\
63.2 \\
70.5 \\
81.3 \\
92.3 \\
97.1\end{array}$ & $\begin{array}{c}0 \\
7.6 \\
15.2 \\
30.5 \\
61.0 \\
91.4\end{array}$ & $\begin{array}{r}0 \\
8.2 \\
17.7 \\
36.6 \\
73.2 \\
109.7\end{array}$ & & $\begin{array}{l}1.000 \\
1.001 \\
1.002 \\
1.002 \\
1.001 \\
1.001\end{array}$ & \\
\hline $\begin{array}{l}\text { (a) For (1), } \\
\text { solution } \\
\text { (b) For }(9) \text {, }\end{array}$ & $\begin{array}{l}\text { reflector } \\
\text { surface; } \\
\text { reflector }\end{array}$ & surfac & $\begin{array}{l}\text { dimensions } \\
\text { to consist }\end{array}$ & $\begin{array}{l}\text { assumed the } \\
\text { of } 9 \text { such } r \\
\text { to the ends }\end{array}$ & me as those & Lng a \\
\hline
\end{tabular}


Pairs of Cylinders (4)

(Does not include the pairs listed in Tables VII and IX)

$$
\mathrm{M}^{2}=32 \mathrm{~cm}^{2}, \mathrm{~S}_{0}=3 \mathrm{~cm}
$$

\begin{tabular}{|c|c|c|c|c|c|c|}
\hline \multirow[b]{2}{*}{ Diameter, cm } & \multirow[b]{2}{*}{$\mathrm{B}^{2}, \mathrm{~cm}^{-2}$} & \multirow[b]{2}{*}{$\mathrm{Ht}, \mathrm{cm}$} & \multicolumn{2}{|c|}{ Pitch, cm } & \multirow{2}{*}{$\mathrm{k}_{\text {eff }}$} & \\
\hline & & & Expti. & Calc. & & \\
\hline 25.4 & $\begin{array}{c}0.027992 \\
\end{array}$ & $\begin{array}{l}28.7 \\
30.7 \\
32.8 \\
34.3 \\
35.8 \\
37.2 \\
38.2 \\
39.1\end{array}$ & $\begin{array}{l}25.7 \\
27.7 \\
31.5 \\
35.3 \\
41.3 \\
50.3 \\
59.6 \\
75.6\end{array}$ & $\begin{array}{l}25.4^{(a)} \\
26.7 \\
31.2 \\
35.8 \\
42.0 \\
50.3 \\
59.6 \\
73.0\end{array}$ & $\begin{array}{l}0.989 \\
0.996 \\
0.999 \\
1.001 \\
1.001 \\
1.000 \\
1.000 \\
0.999\end{array}$ & \\
\hline & 0.024258 & $\begin{array}{l}40.8 \\
44.9 \\
50.0 \\
54.7 \\
64.6 \\
74.5 \\
80.1\end{array}$ & $\begin{array}{l}25.7 \\
27.6 \\
30.5 \\
33.7 \\
42.3 \\
57.0 \\
69.0\end{array}$ & $\begin{array}{l}25.4^{(2)} \\
26.5 \\
30.6 \\
35.2 \\
47.9 \\
66.3 \\
81.2\end{array}$ & $\begin{array}{l}0.991 \\
0.996 \\
1.000 \\
1.003 \\
1.005 \\
1.004 \\
1.003\end{array}$ & \\
\hline & $0.02387^{8}$ & $\begin{array}{l}42.7 \\
58.4 \\
67.6 \\
76.7 \\
90.7\end{array}$ & $\begin{array}{l}26.0 \\
33.3 \\
41.0 \\
48.6 \\
66.3\end{array}$ & $\begin{array}{l}25.4(a) \\
34.5 \\
43.2 \\
53.9 \\
75.8\end{array}$ & $\begin{array}{l}0.989 \\
1.002 \\
1.002 \\
1.003 \\
1.003\end{array}$ & \\
\hline 30.0 & 0.024830 & $\begin{array}{l}26.4 \\
27.7 \\
28.6 \\
29.5 \\
30.9 \\
31.4 \\
31.5 \\
31.6 \\
31.6\end{array}$ & $\begin{array}{r}30.3 \\
33.6 \\
36.7 \\
42.7 \\
60.7 \\
90.4 \\
120.5 \\
135.1 \\
150.0\end{array}$ & $\begin{array}{l}30.0(a) \\
33.0 \\
37.7 \\
45.0 \\
74.8 \\
131.0 \\
179.6 \\
370.4 \\
411.0\end{array}$ & $\begin{array}{l}0.994 \\
0.999 \\
1.002 \\
1.002 \\
1.003 \\
1.002 \\
1.001 \\
1.001 \\
1.001\end{array}$ & \\
\hline - & 0.022242 & $\begin{array}{l}32.9 \\
37.4 \\
38.2 \\
39.5 \\
40.9 \\
41.4 \\
41.4\end{array}$ & $\begin{array}{r}30.3 \\
37.8 \\
45.3 \\
60.2 \\
90.4 \\
120.5 \\
150.0\end{array}$ & $\begin{array}{c}30.4 \\
47.5 \\
54.0 \\
71.3 \\
132.2 \\
- \\
-\end{array}$ & $\begin{array}{l}1.002 \\
1.010 \\
1.005 \\
1.003 \\
1.003 \\
1.002 \\
1.001\end{array}$ & i \\
\hline & 0.019886 & $\begin{array}{l}40.9 \\
48.6 \\
52.3 \\
56.4 \\
60.0 \\
61.3 \\
61.9\end{array}$ & $\begin{array}{r}30.3 \\
37.8 \\
45.3 \\
60.2 \\
90.4 \\
120.5 \\
150.0\end{array}$ & $\begin{array}{c}30.0^{(\mathrm{a})} \\
40.2 \\
50.2 \\
69.3 \\
104.9 \\
137.6 \\
150.0\end{array}$ & $\begin{array}{l}0.995 \\
1.003 \\
1.004 \\
1.003 \\
1.002 \\
1.001 \\
1.000\end{array}$ & \\
\hline 38.1 & 0.028336 & $\begin{array}{l}17.3 \\
17.8 \\
18.0 \\
18.3\end{array}$ & $\begin{array}{l}38.7 \\
43.4 \\
53.4 \\
88.4\end{array}$ & $\begin{array}{l}38.1^{(a)} \\
39.6 \\
44.0 \\
59.4\end{array}$ & $\begin{array}{l}0.989 \\
0.996 \\
0.995 \\
0.997\end{array}$ & \\
\hline & 0.024757 & $\begin{array}{l}20.1 \\
20.8 \\
21.0 \\
21.3 \\
21.5\end{array}$ & $\begin{array}{l}38.6 \\
43.4 \\
48.1 \\
69.7 \\
88.4\end{array}$ & $\begin{array}{l}38.1^{(a)} \\
41.5 \\
45.2 \\
55.1 \\
70.7\end{array}$ & $\begin{array}{l}0.991 \\
0.998 \\
0.998 \\
0.997 \\
0.999\end{array}$ & \\
\hline 50.8 & 0.030167 & $\begin{array}{l}14.7 \\
14.8 \\
14.8\end{array}$ & $\begin{array}{l}51.1 \\
56.1 \\
71.1\end{array}$ & $\begin{array}{c}104.1 \\
- \\
-\end{array}$ & $\begin{array}{l}1.007 \\
1.008 \\
1.005\end{array}$ & \\
\hline & 0.025380 & $\begin{array}{l}16.7 \\
17.0 \\
17.3\end{array}$ & $\begin{array}{l}51.1 \\
61.1 \\
76.0\end{array}$ & $\begin{array}{l}50.8^{(a)} \\
52.4 \\
-\end{array}$ & $\begin{array}{l}0.992 \\
0.996 \\
1.003\end{array}$ & \\
\hline
\end{tabular}

(a) Calculations indicate cylinders would be subcritical at contact.

$$
-25 \text { - }
$$


TABLE VII

$$
\begin{aligned}
& \text { Groups of Cylinders of } \\
& \text { Solution Containing about } 500 \mathrm{~g}^{235} \mathrm{U} / \mathrm{I}(4) \\
& \mathrm{B}_{\mathrm{m}}^{2}=0.030367 \mathrm{~cm}^{-2}, \mathrm{M}^{2}=32 \mathrm{~cm}^{2}, \mathrm{~S}_{0}=2.7 \mathrm{~cm} \\
& \mathrm{~L}=\text { Linear, } \mathrm{T}=\text { Triangular, } \mathrm{S}=\text { Square }
\end{aligned}
$$

\begin{tabular}{|c|c|c|c|c|c|}
\hline \multirow[b]{2}{*}{ Diameter, $\mathrm{Cm}$} & \multirow[b]{2}{*}{ Conf1guration } & \multirow[b]{2}{*}{$\mathrm{Ht}, \mathrm{cm}$} & \multicolumn{2}{|c|}{ P1tch, $\mathrm{cm}$} & \multirow[b]{2}{*}{$k_{\text {eff }}$} \\
\hline & & & Expt1. & Calc. & \\
\hline 12.7 & $7-T$ & $\begin{array}{l}28.7 \\
66.3\end{array}$ & $\begin{array}{l}13.6 \\
15.9\end{array}$ & $\begin{array}{l}12.7^{(a)} \\
14.1\end{array}$ & $\begin{array}{l}0.924 \\
0.947\end{array}$ \\
\hline 15.2 & $7-T$ & $\begin{array}{l}22.6 \\
33.0 \\
51.6 \\
83.8\end{array}$ & $\begin{array}{l}15.9 \\
18.1 \\
20.6 \\
23.2\end{array}$ & $\begin{array}{l}15.2^{(a)} \\
16.6 \\
19.1 \\
21.7\end{array}$ & $\begin{array}{l}0.935 \\
0.958 \\
0.973 \\
0.981\end{array}$ \\
\hline 20.3 & $\begin{array}{l}2-I \\
3-I \\
4-I \\
5-I\end{array}$ & $\begin{array}{r}68.3 \\
45.7 \\
124.5 \\
41.9 \\
96.5 \\
40.1 \\
78.7\end{array}$ & $\begin{array}{l}21.0 \\
21.0 \\
28.2 \\
21.0 \\
28.2 \\
21.0 \\
28.2\end{array}$ & $\begin{array}{l}20.3^{(a)} \\
20.3^{(a)} \\
26.9 \\
20.3^{(a)} \\
28.0 \\
20.4 \\
27.6\end{array}$ & $\begin{array}{l}0.979 \\
0.981 \\
0.995 \\
0.988 \\
0.999 \\
0.992 \\
0.996\end{array}$ \\
\hline 20.3 & $\begin{array}{c}3-T \\
\left(90^{\circ}\right) \\
3-T \\
\left(120^{\circ}\right) \\
3-5\end{array}$ & $\begin{array}{r}27.2 \\
35.1 \\
45.2 \\
55.9 \\
68.8 \\
106.7 \\
36.1 \\
71.3 \\
42.4 \\
87.4 \\
36.1 \\
71.4\end{array}$ & $\begin{array}{l}21.0 \\
23.2 \\
25.7 \\
28.2 \\
30.8 \\
35.9 \\
21.0 \\
28.2 \\
21.0 \\
28.2 \\
21.0 \\
28.2\end{array}$ & $\begin{array}{l}20.3^{(a)} \\
20.3^{(a)} \\
23.5 \\
26.3 \\
28.9 \\
33.9 \\
20.3^{(a)} \\
26.8 \\
20.3^{(a)} \\
26.1 \\
20.3^{(a)} \\
26.8\end{array}$ & $\begin{array}{l}0.938 \\
0.967 \\
0.982 \\
0.988 \\
0.991 \\
0.993 \\
0.967 \\
0.992 \\
0.969 \\
0.993 \\
0.967 \\
0.992\end{array}$ \\
\hline 20.3 & $7-T$ & $\begin{array}{l}18.3 \\
21.6 \\
25.7 \\
29.7 \\
33.5 \\
41.9 \\
55.9\end{array}$ & $\begin{array}{l}21.0 \\
23.2 \\
25.7 \\
28.2 \\
30.8 \\
35.9 \\
43.5\end{array}$ & $\begin{array}{l}20.3^{(a)} \\
21.1 \\
24.1 \\
27.1 \\
30.1 \\
35.4 \\
42.7\end{array}$ & $\begin{array}{l}0.943 \\
0.962 \\
0.977 \\
0.988 \\
0.994 \\
0.997 \\
0.996\end{array}$ \\
\hline 25.4 & $2-I$ & $\begin{array}{l}25.5 \\
29.9 \\
32.6 \\
33.6\end{array}$ & $\begin{array}{c}26.0 \\
35.7 \\
55.8 \\
\infty\end{array}$ & $\begin{array}{l}25.4(a) \\
31.8 \\
47.8\end{array}$ & $\begin{array}{l}0.977 \\
0.993 \\
0.996 \\
0.992\end{array}$ \\
\hline
\end{tabular}

(a) Calculations indicate cylinders would be subcritical at contact. 


\section{TABLE VIII}

Groups of Cylinders of Solution Containing $848^{235} \mathrm{U} / \mathrm{I}^{(4)}$

$$
B_{m}^{2}=0.024384 \mathrm{~cm}^{-2}, M^{2}=32 \mathrm{~cm}^{2}, S_{0}=3.0 \mathrm{~cm}
$$

Dia, $\mathrm{cm}$ Configuration $\mathrm{Ht}, \mathrm{cm}$ Pxptl. Calc. $\mathrm{k}_{\mathrm{eff}}$

$\begin{array}{llllll}15.2 & 7-\mathrm{T} & 31.0 & 16.3 & 15.2^{(\mathrm{a})} & 0.947\end{array}$

$\begin{array}{llll}56.9 & 18.1 & 17.2 & 0.978\end{array}$

$\begin{array}{llll}195.6 & 20.6 & 20.0 & 0.991\end{array}$

$\begin{array}{llllll}20.3 & 3-T & 41.4 & 21.0 & 20.3^{(a)} & 0.945\end{array}$

$\begin{array}{llll}79.3 & 23.2 & 20.3(a) & 0.978\end{array}$

$\begin{array}{llllll}20.3 & 7-T & 28.7 & 23.2 & 22.2 & 0.982\end{array}$

$\begin{array}{llll}45.2 & 28.2 & 28.8 & 1.006\end{array}$

$89.9 \quad 35.9 \quad 37.9 \quad 1.015$

$119.1 \cdot 38.4 \quad 40.6 \quad 1.014$

(a) Calculations indicate cylinders would be subcritical at contact. 
$\underline{T A B L E I X}$

Groups of 24.I-cm-Diameter Cylinders of Solution Containing $87 \mathrm{~g} 235 \mathrm{U} / \mathrm{I}^{(4)}$

\begin{tabular}{|c|c|c|c|c|}
\hline \multirow[b]{2}{*}{ Configuration } & \multirow[b]{2}{*}{$\mathrm{Ht}, \mathrm{cm}$} & \multicolumn{2}{|c|}{ Pitch, $\mathrm{cm}$} & \multirow[b]{2}{*}{$\mathrm{k}_{\mathrm{eff}}$} \\
\hline & & ExptI. & Calc. & \\
\hline $2-I$ & $\begin{array}{r}61.2 \\
80.5 \\
113.0 \\
137.2\end{array}$ & $\begin{array}{l}27.0 \\
32.1 \\
39.7 \\
44.8\end{array}$ & $\begin{array}{l}26.4 \\
32.8 \\
42.1 \\
47.5\end{array}$ & $\begin{array}{l}0.998 \\
1.002 \\
1.003 \\
1.002\end{array}$ \\
\hline $3-I$ & $\begin{array}{r}56.6 \\
84.3 \\
111.3 \\
152.7\end{array}$ & $\begin{array}{l}29.5 \\
39.7 \\
49.8 \\
62.5\end{array}$ & $\begin{array}{l}30.8 \\
43.4 \\
53.7 \\
66.3\end{array}$ & $\begin{array}{l}1.005 \\
1.006 \\
1.004 \\
1.002\end{array}$ \\
\hline $4-L$ & $\begin{array}{l}57.7 \\
76.2 \\
97.8\end{array}$ & $\begin{array}{l}32.1 \\
39.7 \\
49.8\end{array}$ & $\begin{array}{l}34.1 . \\
43.6 \\
53.6\end{array}$ & $\begin{array}{l}1.007 \\
1.007 \\
1.004\end{array}$ \\
\hline $5-I$ & $\begin{array}{l}55.1 \\
71.9 \\
92.0\end{array}$ & $\begin{array}{l}32.1 \\
39.7 \\
49.8\end{array}$ & $\begin{array}{l}34.2 \\
43.4 \\
53.5\end{array}$ & $\begin{array}{l}1.008 \\
1.007 \\
1.004\end{array}$ \\
\hline $6-L$ & $\begin{array}{l}54.1 \\
88.4\end{array}$ & $\begin{array}{l}32.1 \\
49.8\end{array}$ & $\begin{array}{l}34.5 \\
53.3\end{array}$ & $\begin{array}{l}1.009 \\
1.004\end{array}$ \\
\hline $2 \times 2-5$ & $\begin{array}{r}40.1 \\
69.1 \\
120.4 \\
158.8\end{array}$ & $\begin{array}{r}32.1 \\
49.8 \\
80.3 \\
100.6\end{array}$ & $\begin{array}{r}32.4 \\
53.7 \\
85.9 \\
104.0\end{array}$ & $\begin{array}{l}1.002 \\
1.007 \\
1.003 \\
1.001\end{array}$ \\
\hline $3-T$ & $\begin{array}{r}34.0 \\
51.6 \\
71.4 \\
92.2 \\
126.2 \\
152.7\end{array}$ & $\begin{array}{l}27.0 \\
34.6 \\
44.8 \\
54.9 \\
70.2 \\
80.3\end{array}$ & $\begin{array}{l}24.1^{(a)} \\
35.2 \\
47.4 \\
59.1 \\
74.9 \\
84.7\end{array}$ & $\begin{array}{l}0.981 \\
1.002 \\
1.005 \\
1.004 \\
1.003 \\
1.002\end{array}$ \\
\hline $7-T$ & $\begin{array}{l}30.7 \\
51.1 \\
83.6\end{array}$ & $\begin{array}{l}32.1 \\
49.8 \\
80.3\end{array}$ & $\begin{array}{l}32.7 \\
53.7 \\
85.9\end{array}$ & $\begin{array}{l}1.005 \\
1.011 \\
1.005\end{array}$ \\
\hline
\end{tabular}

(a) Calculations indicate cylinders would be subcritical at contact. 


\section{TABLE X}

Groups of 15.24-cm-Diameter Cylinders of Solution Containing $380 \mathrm{~g} 235_{\mathrm{U} / 1}(4,7)$

$\mathrm{B}_{\mathrm{m}}^{2}=0.026822 \mathrm{~cm}^{-2}, \mathrm{M}^{2}=35 \mathrm{~cm}^{2}, \mathrm{~S}=3.1 \mathrm{~cm}$
$\mathrm{~T}=$ Triangular, $\mathrm{S}=$ Square

\begin{tabular}{|c|c|c|c|c|}
\hline \multirow[b]{2}{*}{ Configuration } & \multirow[b]{2}{*}{ Ht, $\mathrm{cm}$} & \multicolumn{2}{|c|}{ Pitch, $\mathrm{cm}$} & \multirow{2}{*}{$k_{\text {eff }}$} \\
\hline & & ExptI. & Calc. & \\
\hline $2 \times 2-5$ & $\begin{array}{r}66.9 \\
108.7\end{array}$ & $\begin{array}{l}15.9 \\
16.5\end{array}$ & $\begin{array}{l}15.2^{(a)} \\
15.2^{(a)}\end{array}$ & $\begin{array}{l}0.942 \\
0.954\end{array}$ \\
\hline $3 \times 3-5$ & $\begin{array}{r}51.5 \\
55.0 \\
77.9 \\
101.6 \\
126.0\end{array}$ & $\begin{array}{l}19.4 \\
19.9 \\
21.4 \\
22.4 \\
23.2\end{array}$ & $\begin{array}{l}19.6 \\
20.0 \\
21.8 \\
23.0 \\
23.8\end{array}$ & $\begin{array}{l}1.006 \\
1.003 \\
1.007 \\
1.009 \\
1.009\end{array}$ \\
\hline $4 \times 4-5$ & $\begin{array}{r}50.1 \\
76.2 \\
101.8 \\
128.0\end{array}$ & $\begin{array}{l}22.1 \\
25.1 \\
27.0 \\
28.2\end{array}$ & $\begin{array}{l}23.4 \\
27.2 \\
29.2 \\
30.6\end{array}$ & $\begin{array}{l}1.025 \\
1.035 \\
1.035 \\
1.033\end{array}$ \\
\hline $7-T$ & $\begin{array}{l}24.8 \\
39.1 \\
69.8 \\
99.5\end{array}$ & $\begin{array}{l}15.9 \\
18.1 \\
20.6 \\
21.9\end{array}$ & $\begin{array}{l}15.2^{(a)} \\
17.2 \\
20.2 \\
21.8\end{array}$ & $\begin{array}{l}0.948 \\
0.978 \\
0.994 \\
0.999\end{array}$ \\
\hline $19-\mathrm{T}$ & $\begin{array}{r}50.1 \\
76.2 \\
101.6 \\
127.0\end{array}$ & $\begin{array}{l}24.5 \\
28.1 \\
30.6 \\
32.4\end{array}$ & $\begin{array}{l}26.5 \\
30.8 \\
33.7 \\
35.4\end{array}$ & $\begin{array}{l}1.041 \\
1.038 \\
1.035 \\
1.035\end{array}$ \\
\hline
\end{tabular}

(a) Calculations indicate cylinders would be subcritical at contact. 


\section{TABLE XI}

Groups of 24.13-cm-Diameter Cylinders of Solution Containing about $890 \mathrm{~g} U(4.9) / I^{(8)}$

$$
\mathrm{B}_{\mathrm{m}}{ }^{2}=0.011970 \mathrm{~cm}^{-2}, \mathrm{M}^{2}=31 \mathrm{~cm}^{2}, \mathrm{~S}_{0}=3.00 \mathrm{~cm}
$$

$\mathrm{T}=$ Triangular, $\mathrm{S}=$ Square

\begin{tabular}{|c|c|c|c|c|}
\hline \multirow[b]{2}{*}{ Configuration } & \multirow[b]{2}{*}{$\mathrm{Ht}, \mathrm{cm}$} & \multicolumn{2}{|c|}{ Pitch, $\mathrm{cm}$} & \multirow[b]{2}{*}{$k_{e f f}$} \\
\hline & & Expt1. & Calc. & \\
\hline $3 \times 3-5$ & $\begin{array}{r}61.0 \\
122.0 \\
142.2\end{array}$ & $\begin{array}{l}26.1 \\
29.6 \\
30.3\end{array}$ & $\begin{array}{l}24.1^{(a)} \\
27.3(24.3)^{(b)} \\
28.1(24.9)\end{array}$ & $\begin{array}{l}0.964(0.942)^{(b)} \\
0.978(0.955) \\
0.977(0.954)\end{array}$ \\
\hline $4 \times 4-5$ & $\begin{array}{r}61.0 \\
122.0 \\
142.2\end{array}$ & $\begin{array}{l}28.3 \\
33.9 \\
35.1\end{array}$ & $\begin{array}{l}28.2(26.3) \\
33.9(31.6) \\
35.1(32.5)\end{array}$ & $\begin{array}{l}0.998(0.979) \\
1.002(0.979) \\
1.000(0.979)\end{array}$ \\
\hline $5 \times 5-s$ & $\begin{array}{r}61.0 \\
122.0 \\
142.2\end{array}$ & $\begin{array}{l}30.0 \\
37.1 \\
38.9\end{array}$ & $\begin{array}{l}30.7(29.4) \\
39.5(36.5) \\
41.3(38.2)\end{array}$ & $\begin{array}{l}1.008(0.991) \\
1.015(0.996) \\
1.015(0.996)\end{array}$ \\
\hline $7-T$ & $\begin{array}{r}61.0 \\
122.0 \\
142.2\end{array}$ & $\begin{array}{l}26.6 \\
29.2 \\
29.8\end{array}$ & $\begin{array}{l}24.1 \text { (a) } \\
25.4(24.1)^{(a)} \\
25.9(24.1)^{(a)}\end{array}$ & $\begin{array}{l}0.949(0.926) \\
0.962(0.939) \\
0.963(0.939)\end{array}$ \\
\hline $19-\mathrm{T}$ & $\begin{array}{l}122.0 \\
142.2\end{array}$ & $\begin{array}{l}37.9 \\
39.5\end{array}$ & $\begin{array}{l}39.4(37.2) \\
40.7(38.4)\end{array}$ & $\begin{array}{l}1.013(0.994) \\
1.010(0.989)\end{array}$ \\
\hline
\end{tabular}

(a) Calculations indicated sylinders would be subcritical at contact.

(b) Values in parentheses calculated with $S_{0}=2.50 \mathrm{~cm}$, $\mathrm{B}_{\mathrm{m}}{ }^{2}=0.012536$. 


\section{TABIE XII}

Cylinder (25.4-cm-dia) and Slab (15.1-cm-thick, 120.6-cm-long) of Solution Containing $78 \mathrm{~g} 235 \mathrm{U} / \mathrm{I}^{(4)}$

\begin{tabular}{|c|c|c|c|c|c|c|}
\hline \multirow{2}{*}{$\mathrm{Ht}, \mathrm{cm}$} & \multicolumn{2}{|c|}{$\mathrm{B}_{\mathrm{m}}^{2}=0.024793 \mathrm{~cm}^{-2}, \mathrm{M}^{2}$} & $=32 \mathrm{~cm}^{2}$ & $\begin{array}{c}S_{0}= \\
\beta_{c}\end{array}$ & \multicolumn{2}{|c|}{, $S_{0}=2.70 \mathrm{~cm}$} \\
\hline & & 0.355 & 0.235 & 0.360 & 0.231 & 0.934 \\
\hline $\begin{array}{l}30.7 \\
47.8\end{array}$ & $\begin{array}{r}15.7 \\
15.7\end{array}$ & 0.246 & 0.163 & 0 & $\begin{array}{l}0.237 \\
0.196\end{array}$ & $\begin{array}{l}1.001 \\
1.010\end{array}$ \\
\hline 58. & 31.0 & 0.183 & 0.121 & 0.113 & 0.153 & $\begin{array}{l}1.010 \\
1.010\end{array}$ \\
\hline 66.5 & 46.2 & 0.140 & 0.093 & $\begin{array}{l}0.085 \\
0.056\end{array}$ & 0.089 & 1.006 \\
\hline 79.3 & 76.7 & 0.087 & 0.058 & $\begin{array}{l}0.056 \\
0.039\end{array}$ & 0.058 & 1.004 \\
\hline 89.2 & 107 & 0.059 & $\begin{array}{c}0.039 \\
\text { ed slab }\end{array}$ & & & 1.000 \\
\hline 5.8 & $\infty$ & Isolat & $\begin{array}{l}\text { ed slab } \\
\text { ed cyli }\end{array}$ & nder & & 1.000 \\
\hline 147.3 & $\infty$ & & & & & \\
\hline
\end{tabular}


APPENDIX A - FORTRAN Listing

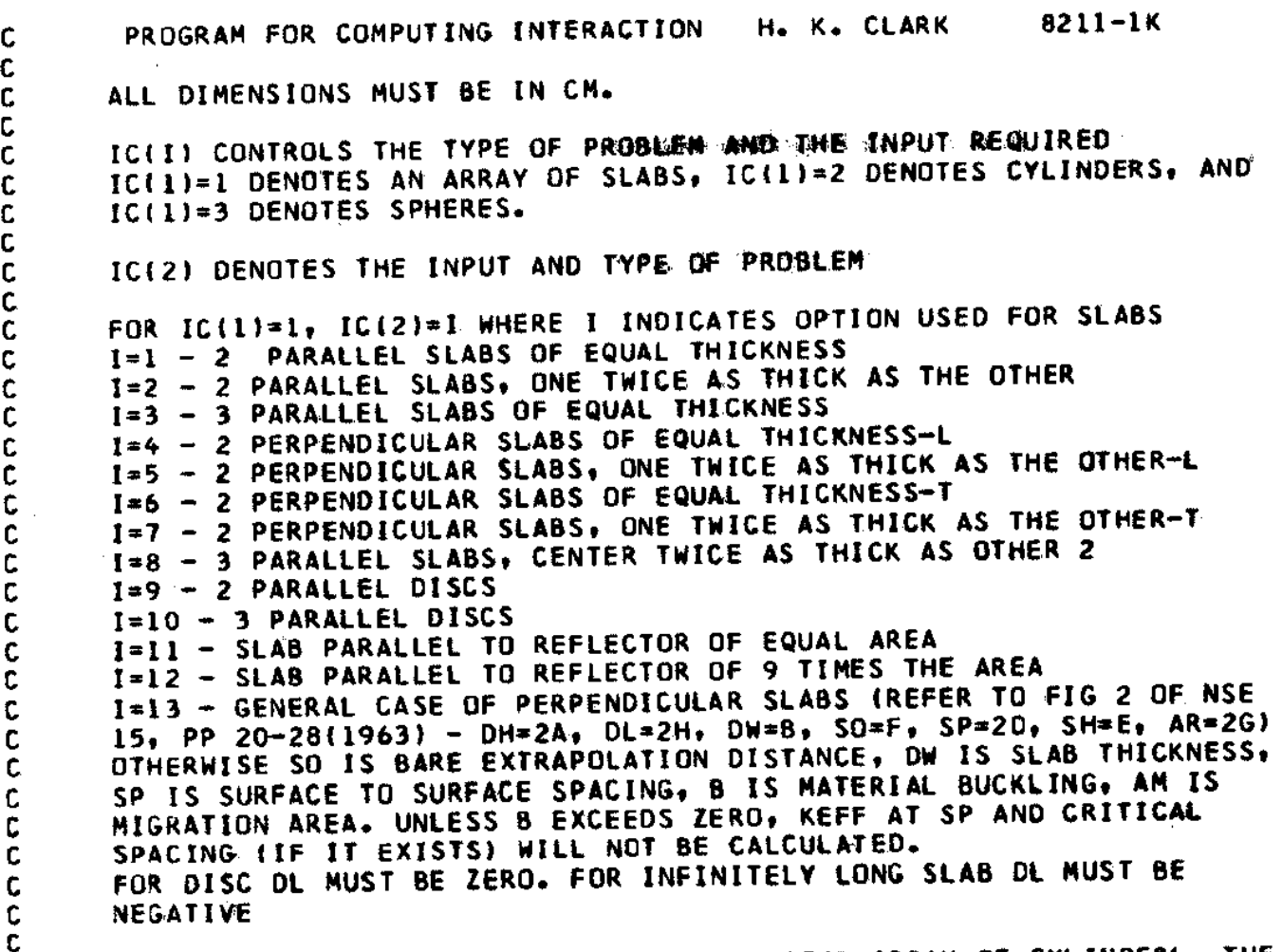

FOR IC $(1)=2$, IC $(2)=0$ INDICATES A REFLECTED ARRAY OF CYLINDER! THE INPUT CONSISTS OF THE NUMBER OF SYMMETRICALLY EQUIVALENT POSITIONS INPUT CONSISTS OF THE NUMBER OF SYME, NUMBER OF UNITS, DIAMETER, HEIGHT, AREA OF ENCLOS ING SURFACES. MINIMUM AXIS-TO-AXIS SPACING, ALBEDO OF REFLECTOR, BARE AND AXIAL EXTRAPOLATION DISTANCES, MATERIAL BUCKLING, MIGRATION AREA. IF CYLINDER HEIGHT IS INFINITE, HU IS MADE ZERO OR NEGATIVE AND SR IS THE REFLECTOR AREA PER UNIT HEIGHT.

FOR IC $(1)=3, I C(2)=0$ INDICATES A REFLECTED ARRAY OF SPHERES. THE INPUT CONSISTS OF THE NUMBER OF SYMMETRY TYPES, NUMBER OF UNITS, DIAMETER, MINIMUM CENTER-TO-CENTER SEPARATION, TOTAL AREA OF REFLECTING SURFACES, ALBEDO OF REFLECTOR, BARE EXTRAPOLATION DISTANCE, MATERIAL BUCKLING, AND MIGRATION AREA. FOR IC (1)=3. IC 12$\}=1$ INDICATES A REFLECTED ARRAY OF CYLINDERS TO BE TREATED AS SPHERES. INPUT IS NN, NO, UNITS, CYLINDER DIAMETER HEIGHT, INTERNAL VOLUME, WALL THICKNESS, SURFACE-TO-SURFACE SEPARATIDN, ALBEDO OF REFLECTOR, BARE EXTRAPOLATION DISTANCE, MATERIAL BUCKLING AND MIGRATION AREA.

TREATING THOMAS EXPERIMENTS AS CUBIC ARRAYS OF SPHERESI

IC(3) DENOTES NUMBER OF COMMENT CARDS

IC $(4)$ DENOTES NUMBER OF SPACINGS TO BE READ IN FOR CYL AND SPHERE IF IC $(4)=0$ NUMBER IS ASSUMED NOT TO CHANGE AND SDU AND WDI ARE NOT READ IN.

IC(5) DENOTES FORMAT FOR WUF. IF IC $(5)=0$, FORMAT IS $6 F 2.0,60 F 1.0$

OTHERWISE FORMAT IS $24 F 3.2$ 

C THE WST AND WUF CARDS ARE READ ONLY IF NM CHANGES NM=O CALLS FOR
$C$
THE IC CARD TO BE READ NEXT
$C$ 1 MATERIAL MIGRATION EXTRAPOLATION DISTANCE INITIAL $2120 H$
3CKLING

323 FORMAT $15, F 8,3, F 9,3, F 7,3, F 8,2, F 9,4, F 10,4, F 11,6, F 11,2, F 13,2, F 7.2, F$ $18.2, F 11.4)$

324 FORMATII2OHIARRAYS OF SPHERES. INTERACTION CALCULATED WITH COSINE IOISTRIBUTION FOR CURRENT EMITTED FROM SPHERICAL SURFACE

325 FORMATILOHO NO. DIA/MIN PITCH REFL/SPH REFL FINAL IATERIAL MIGRATION EXTRAPOLATION OISTANCE INITIAL

$2120 \mathrm{H}$ UNITS INITIAL FINAL AREA ALBEDO ALBEDO BUCKLING 3 AREA BARE CRIT FINAL KEFF

326 FORMATII5,2F8,3,F9.2, F13,4,F10,4,F11.6,F1 1.2,F13.2,F7, 2,F8,2,F11 1.41

327 FORMAT196HIARRAYS OF SLABS. COSINE DISTRIBUTION ASSUMED FOR CURRE INT EMITTED FROM SURFACE.

328 FORMATI 12 OHO DIMENSIONS SEPARATION FRACTIONS REACHI ING OTHER SURFACES EXTRPLTN DISTANCES REFL,

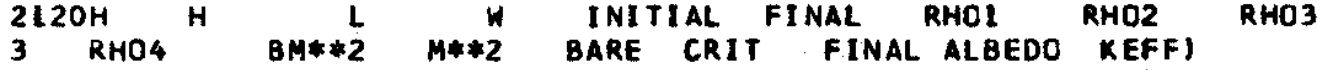

329 FORMATIF7.2,F8,2,F7.2,F8,2,F8.2,4F8,4,F10,6,F7.2,F6.2,2F7.2,F6, 2,F 17.31

330 FORMAT $1120 H O R E F E R$ TO NUCLEAR SCIENCE AND ENGINEER ING, VOLUME 15, N 10. 1. JANUARY $1963, F I G 2$, P 23 FOR MEANING OF SYMBOLS $2120 \mathrm{H}$ $2+$ 2A

331 FORMATIIPTE 15,4, OPF 12.4) DIMENSION IC $(10), C W(108), \operatorname{SOU}(50), W D I(50), W U F(50,10,10), W S T(10)$ IFISENSE LIGHT I) 1,2

1 CALL EXIT

2 CALL EFTM(16)

NTIN=5

NTOUT $=6$

3 READ INPUT TAPE NTIN,301, (IC(I),I=1,5)

$N M=0$

$I P=0$

IF (IC(1) $1,1,4$

$$
-34-
$$




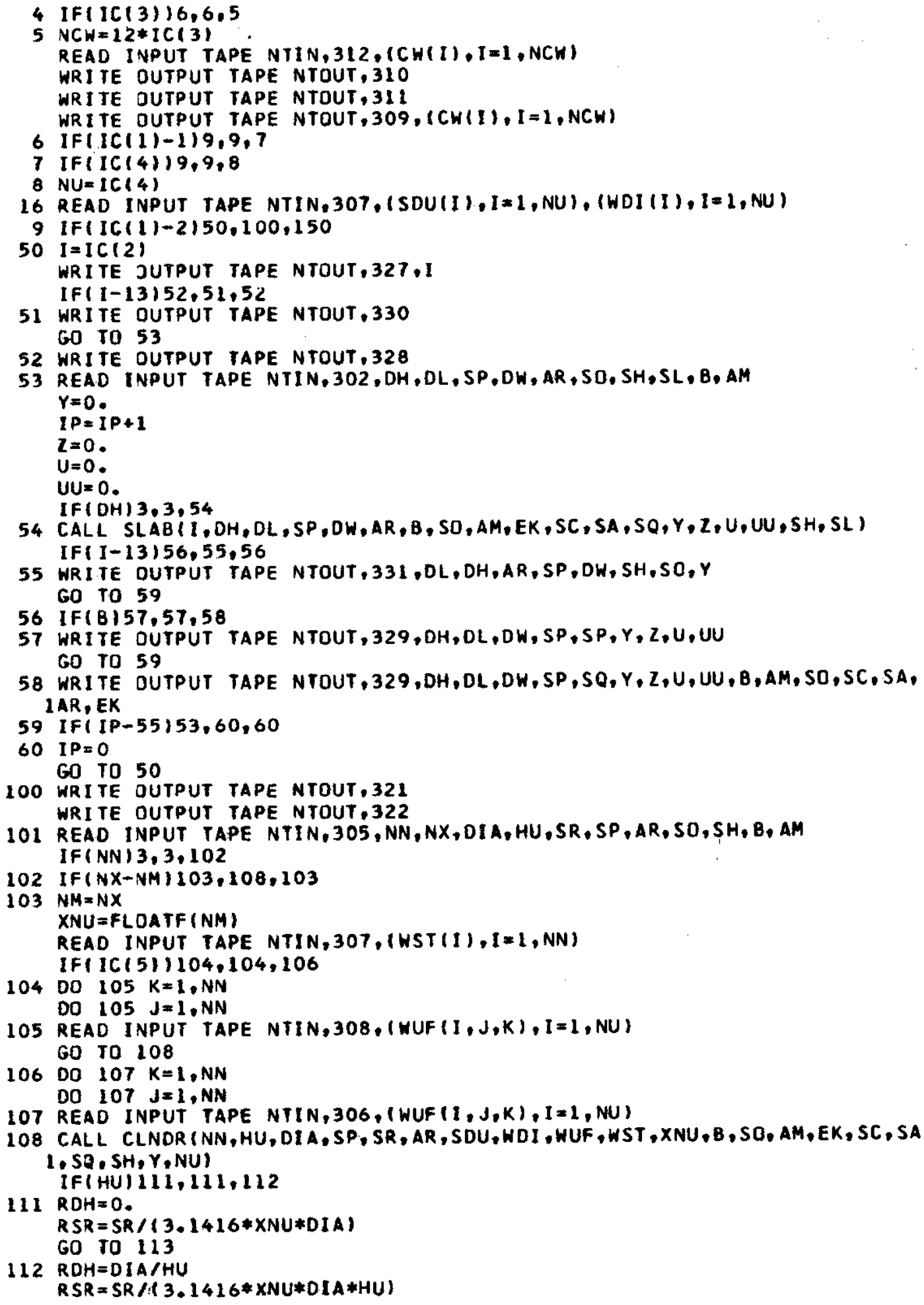


$113 R D P=D I A / S P$

$R D Q=D I A / S Q$

$I P=I P+1$

IF(B) 109,109,110

109 WRITE OUTPUT TAPE NTOUT, 323,NM,RDH,RDP,RDP,RSR, AR,Y GO TO 114

110 WRITE OUTPUT TAPE NTOUT, 323,NM,RDH,ROP,RDQ,RSR,AR, $, B, A M, S O, S C, S A$, IEK

$114 I F(I P-55) 101,115,115$

115 IP $=0$

Go TO 100

150 WRITE OUTPUT TAPE NTOUT, 324

WRI TE DUTPUT TAPE NTOUT, 325

151 IF(IC( 2$)) 152,152,153$

152 READ INPUT TAPE NTIN,303,NN,NX,DIA,SP,SR,AR,SO,B, AM IF ( NN) $3,3,155$

153 READ INPUT TAPE NTIN,305,NN,NX,DIA,HU,VOL,TH,STS, AR, SO, B, AM IF ( NN) 3, 3, 154

$154 S P=(10 I A+S T S) * * 2 *(H U+S T S)) * *(1, / 3.1$

$D I A=2 * *($ VOL $* *(1) / 3) / 11.611991+.T H)$

$S R=F L O A T F(N X) * *(1.13) * S$.

$S R=6 . * S R * * 2$

$155 I F(N X-N M) 156,161,156$

$156 N M=N X$

XNU $=$ FLOA TF $(N M)$

READ INPUT TAPE NTIN,307, (WSTII),I=1,NN)

IFI ICI 5 ) 157,157,159

$15700158 K=1, N N$

DO $158 \mathrm{~J}=1, \mathrm{NN}$

158 READ INPUT TAPE NTIN,308, (WUF $(I, J, K), I=1, N U)$

GO TO 161

$15900160 K=1, N N$

DO $160 \mathrm{~J}=1, N \mathrm{~N}$

160 READ INPUT TAPE NTIN,306, (WUF $(I, J, K), I=1, N U)$

161 CALL SPHEREINN, DIA,SP, SR, AR, SDU, WDI, WUF, WST, XNU, B, SO, AM, EK, SC, SA,

10, Y,NUI

$R D P=D I A / S P$

$R D 2=D I A / S O$

$R S R=S R /(3.1416 * X N U * 01 A * * 2)$

$I P=I P+1$

IF(B) $162,162,163$

162 WRITE DUTPUT TAPE NTOUT, 326,NM,RDP,RDP,RSR,AR,Y GO TO 164

163 WRITE DUTPUT TAPE NTOUT,326,NM,RDP,RDQ,RSR,AR,Y,B,AM,SO,SC, SA, EK

164 IF (IP-55) 151,165,165

$165 I P=0$

GO TO 150

END $(1,0,0,0,0)$ 
SUBROUTINE SLAB H. K. CLARK 8211-1K

SUBROUTINE SLABII,DH,OL,SP,OW,AR,B,SO,AM,EK,SC,SA,SQ,Y, Z,U,UU,SH,S

1L)

$S Q=S P$

IF $(B) 2,2,1$

1 IFIDLI9,3,4

$3 B W=$ SQRTF $(B-(4.8096 /(D H+2 * * S H)) * 2)$

GO TO 5

$4 B W=$ SORTF $(B-9.8696044 *(1, /(D H+2 * * S H) * * 2+1 . /(D L+2 * * S L) * 2)$

GD TO 5

$9 B W=S Q R T F(B-9.8696044 *(1 . /(D H+2 . * S H) * 2))$

$5 S C=1.5707963 / B W-.5 * D W$

$S A=S C$

$S M=1.5707963 / B W$

$S B=0$.

$I K=0$

$A L * 2 * * B W * S O$

$B K=1++A M * B$

TS $=$ SINF(AL)

$T C=\operatorname{COSF}(A L)$

$2 \quad P=0$.

$Q=0$.

IF( DL $16,6,7$

$6 R=0$.

GO TO $B$

$7 \mathrm{R}=\mathrm{DH} / \mathrm{DL}$

$8 T=.5$

$v=1$.

GO to $(60,60,60,61,62,64,65,60,67,67,68,69,73), I$

$60 \mathrm{~S}=\mathrm{SQ} / \mathrm{DL}$.

CALL NTRCT $(P, Q, R, S, T, V, U, Z, Y, Z X)$

GO TO 10

$61 \quad P W=D W$

GO TO 63

$62 P H=.5 * D W$

$63 \mathrm{P}=\mathrm{SQ} / \mathrm{DL}$

$R=D L / D H$

$S=(D L-P H) / D H$

CALL NTRCT $\{P, Q, R, S, T, V, W, X, Y, Z)$

$P=0$.

$Q=.5 *(D L-P W) / P W$

$R=D H / P W$

$S=S Q / O L$

$V=D L / P W$

CALL NTRCT $(P, Q, R, S, T, V, H, X, Y, Z Z)$

$Q=0$.

$R=P W / D H$

$S=S Q / D H$

$V=1$.

CALL NTRCT $(\theta, Q, R, S, T, V, H, X, Y, 2 Y)$

$P=(D L-P W) / P W$

$C A L L N T R C T\{P, Q, R, S, T, V, W, X, Y, Z X)$

$U=1 .-2 \cdot * 2 Z-2 \gamma-2 X$

$U=U * P W / D L$

$Y=Z+U$

GO TO 10

$64 P W=D W$

601066

$65 \mathrm{PW}=.5 * 0 \mathrm{~W}$

$66 P=S Q / D L$

$R=D L / D H$ 
$S=.5 *(D L-P W) / 0 H$

CALL NTRCT $(P, Q, R, S, T, V, H, X, Y, Z)$

$P=0$.

$R=D H / P H$

$S=S Q / D L$

$V=D L / P W$

$C A L L N T R C T(P, Q, R, S, T, V, H, X, Y, 2 Z)$

$P=.5 *(D L-P W) / P W$

$R=P W / D H$

$S=S Q / D H$

$\forall=1$.

CALL NTRCT $(P, Q, R, S, T, V, W, X, Y, Z Y)$

$U=1 \cdot-2 * *(2 Z+Z Y)$

$U=.5 * U * P W / D L$

$Y=1.4142136 *(U+2)$

GO TO 10

$67 \mathrm{~W}=S Q / D H$

$Y=1,+2 * w * * 2-2, * W * \operatorname{SOR} \operatorname{TF}(1, * W * * 2)$

60 ro 10

$68 S=S Q / D L$

CALL NTRCT $(P, Q, R, S, T, V, U, U U, Z, Y)$

$Y=A R * Z * * 2$

60 TO 10

$69 S=S Q / D L$.

$P=0$.

$\forall=1$.

CALL NTRCT $(P, Q, R, S, T, V, W, X, Y Y, Y)$

$P=1$.

CALL NTRCT $(P, Q, R, S, T, V, 2 H, 2 X, 2 Y, 22)$

$R=\mathrm{DL} / \mathrm{DH}$

$S=S Q / D H$

CALL NTRCT $(P, Q, R, S, T, V, Z W, Z X, Y, Z Y)$

$P=0$.

$Q=.5$

$S=.5 * S Q \mathrm{AOH}$

$V=2$.

CALL NTRCT $(P, Q, R, S, T, V, Z W, U, Y, Z X)$

$R=D H / D L$

$S=.5 * 50 / D L$

CALL NTRCT $(P, Q, R, S, T, V, U U, U, Y, Z W)$

IFI DH-DL I 70,70,71

$70 Z=1 \cdot-W-Z Z-2 \cdot * Z X-Y Y$

$U=1 .-X-Z Y-2 \cdot * 2 W-Y Y$

Go To 72

$71 Z=1 \cdot-X-Z Z-2 \cdot * Z X-Y Y$ $U=1 \cdot-W-Z Y-2 * * Z W-Y Y$

$72 P=1$.

$Q=0$.

$S=S Q / 13 . * \mathrm{DH}$

$V=3$.

$\mathrm{R}=\mathrm{DL} / \mathrm{DH}$

CALL NTRCT $(P, Q, R, S, T, V, H, X, Y, Z H)$

$R=D H / D L$

$S=S Q /(3, * D L)$

CALL NTRCT(P,Q,R,S,T, Y,W, $X, Y, Z X)$

$U U=.25 *(1,-2 \cdot *(Z W+Z X+Z+U)-Y Y)$

$Y=A R *(Y Y * * 2+2 * *(U * * 2+Z * * 2+2 * U U * * 2))$

GO TO 10

$73 \quad P=O W / O H$

$Q=S O / D L$

$S=S P / A R$ 
$T=S H / S P$

$V=A R / D L$

CALL NTRCT $(P, Q, R, S, T, V, W, X, Z, Y)$

IF(ABSF $(V-1)+Q+,A B S F(T-.5)+P\{80,74,80$

74 IFIR-1.) 75, 76,76

$75 Y=W$

GO TD 60

$76 Y=X$

60 TO 80

$10 I F(B), 80,80,11$

11 GO TO $(12,13,13,12,13,13,13,13,12,13,12,12), 1$

$12 F A=T S /(T C-Y)$

IF(FA) $21,22,22$

$21 S A=(1.5707963+A \operatorname{TANF}(-1 \cdot / F A)) /(2 \cdot * B H)$

GO TO 50

$22 S A=A T A N F(F A) /(2, * B W)$

GO TO 50

$13 \mathrm{SD}=\mathrm{SA}$

14 GO TO $(12,15,16,12,15,16,15,15,12,16,12,12), 1$

15 FS: SINF (BW*SA)

$F C=\operatorname{COSF}(B H * S A)$

GO TO 17

$16 F S=S I N F(2, * B W * S A)$

$F C=C O S F(2, * B W * S A)$

17 CO TO $(12,18,19,12,18,19,18,20,12,19,12,12), 1$

$18 F A=T C-(F C * 2-F S * 2) * T S /(2, * F S * F C)$

$F A O=.5 * B W * T S /(F C * F S) * * 2$

GO TO 25

$19 F A=(F S * T C-F C * T S) /(F S * T C+F C * T S)$

$F A D=4 * B W * T S /(T C *(F S+T S * F C / T C) * 2)$

GO TO 25

20 DEN $=2 * * T C * F C * S+T S *(F \cdot C * * 2-F S * * 2)$

$F A=(2 . * F S * F C-T S) / D E N$

$F A D=2 . * B W * T S *(1,+T C *(F C * * 2-F S * 2)-2 * T S * F S * F C) / D E N * 2$

60 TO 25

25 GO To $(12,26,27,12,26,27,28,26,12,27,12,12), I$

$26 F B=T C+F S * T S / F C$

$F B D=T S * B W / A C * * 2$

GO TO 35

$27 F B=(F . S-T S) / F . S$

$F B D=2 . * B W * F C * T S / F S * * 2$

607035

$28 F B=(F C-T S) /(T C * F C-T S * F S)$

$F B D * B W * T S *(1,-T C * F S-T S * F C) /(T C * F C-T S * F S) * 2$

60 to 35

$35 S A=S D+(Y * * 2-F A * F B) /(F A * F B D+F B * F A D)$

IF ( $S A-S O) 36,58,58$

$36 S A=.5 *(S O+S D)$

60 TO 13

58 IF( SM-SA ) 59,37,37

$59 S A=.5 *(S M+S D)$

Go 1013

37 IF(ABSF(SA-SD)-.005) $50,13.13$

50 IF(IK) $51,51,52$

$51 E K=B K /(1 .+A M *(B-B W * 2+9.8696044 /(D W+2 *(S A) * * 2))$

52 IF(SC-SO) $57,57,56$

$571 K=10$

$56 \quad I K=I K+1$

IF $(I K-10) 55,55,80$

55 I $F(S A-S B) 53,80,53$

53 IF(ABSF (SA-SC)-.005) $80,54,54$

54 CALL SEP $(0,, S C, S A, S B, S P, S Q, I K)$ GO TO $(60,60,60,63,63,66,66,60,67,67,68,69), I$

BO RETURN END $(1,0,0,0,0\}$ 







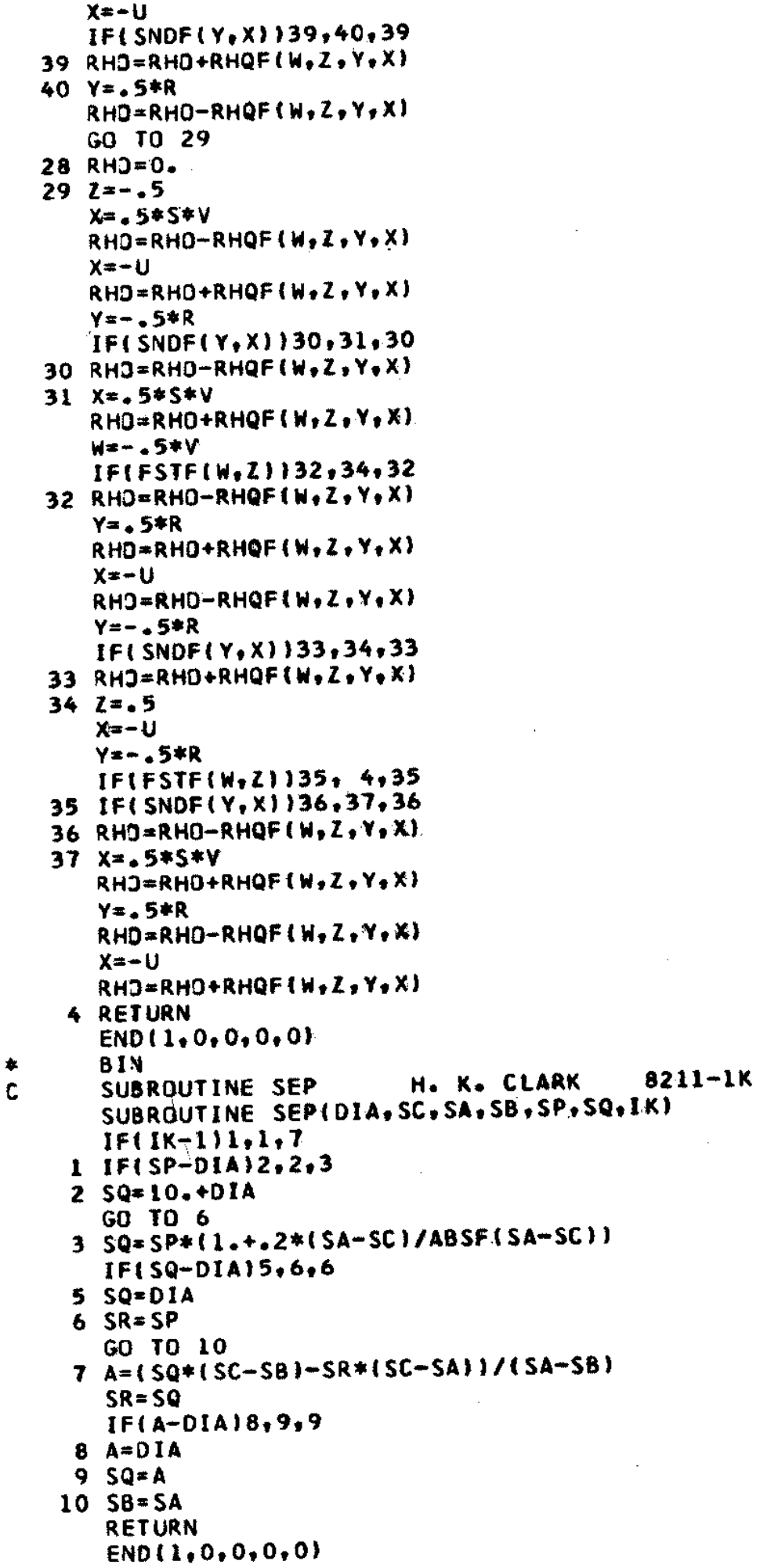


1 IF ( SR ) $2,2,24$

$24 S R=S R-1.5708 * D I A * * 2 * \times N U$

$2 R U=.5 * D I A$

DO $471=1 . N U$

DO $45 \mathrm{~J}=1, \mathrm{NM}$

DO $45 \mathrm{~K}=1, \mathrm{NM}$

45 SMA $=$ SMA +WUF $(1, J, K)$ IF( ABSF ( SMA-SMB) -.000001$) 47,47,46$

$46 \mathrm{~N}=\mathrm{I}$ SMB $=$ SMA

47 CONTINUE IF( $B) 48,48,51$

51 IFI HU $153,53,52$

$52 B R=$ SQR TF. $(B-9.8696044 /(H U+2, * S H) * * 2)$

GO TO 54

$53 B R=S O R T F(B)$

$54 \mathrm{SC}=2.4048 / B R-R U$ $S M=2 \cdot 4048 / B R$

$S B=0$.

$I K=0$

$A L=B R * S O$

$B K=1,+A M * B$

SAISC

DUM $=$ BE SJF $(2,4048-A L, 0,1,113, X L O C F(T T(1)))$

$T J=T T(1) / T T(2)$

48 SUM $=0$.

DO $3 i=1, N$

$S=S Q R T F(S D U(I)) * S$ Q

$A A=R U / S$

$H(I)=C L D R C T(A A, 0$.

$34 S U M=S U M+H(I) * H D I(1)$

IF( 1.-SUM) 5,4,3

3 CONTINUE

$L=N$

Co To 6

$41=1$

GO TO 6

$5 L=I$

$H(L)=(1,-S U M+H(L) * H D I(L) / / H D I(L)$

6 IF (HU) $10,10,11$

10 SE $=0$.

GO TO 12

11 SE $=$ RU/HU

12 AA*RU/ISQRTF (SOU(L) $* S O)$

$H(L)=H(L) * C L D R C T(A A, S E) / C L D R C T(A A, 0$.

$L=L-1$

IFIL)7,7,8

8 DO $9 I=1, L$

S=SQRTF( SDU(I)) *SE

$A A=R U / S$

$9 H(I)=C L D R C T(A A, S E)$

$7 \mathrm{~L}=\mathrm{L}+\mathrm{L}$ 


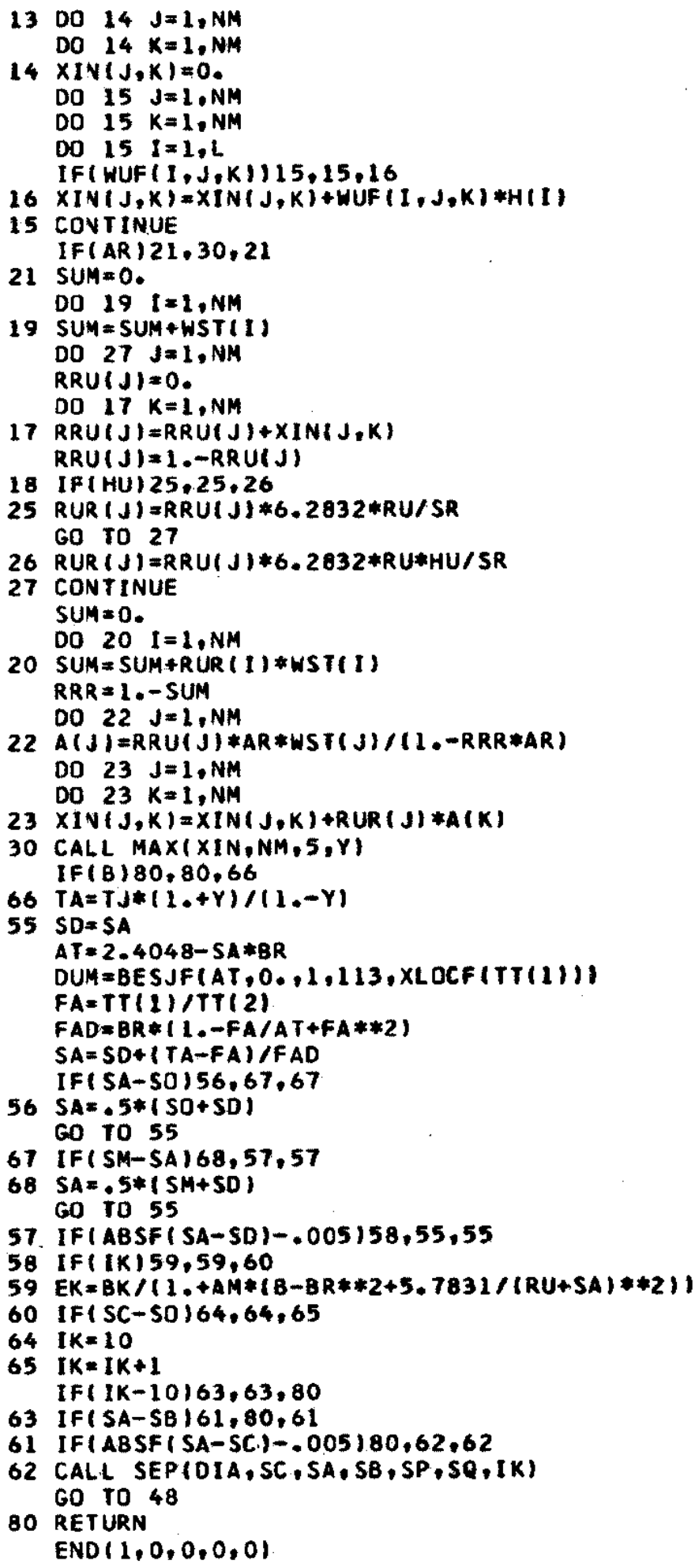

$20 S U M=S U M+R U R(I) * W S T(I)$

$R R R=1 .-S U M$ DO $22 \mathrm{~J}=2, \mathrm{NM}$

$22 A(J)=R R U(J) * A R * W S T(J) /(1 \cdot-R R R * A R)$

DO $23 \mathrm{~J}=1, \mathrm{NM}$ DO $23 \mathrm{~K}=1, \mathrm{NM}$

$23 X I N(J, K)=X I N(J, K)+R \cup R(J) * A(K)$

30 CALL MAX(XIN,NM, S,Y) IF (B) $80,80,66$

$66 T A=T J *(1 \bullet+Y) /(1,-Y)$

$55 \mathrm{SD}=5 \mathrm{~A}$

$A T=2.4048-S A * B R$

DUM $=$ BES JF $(A T, 0,1,113, X L D C F(T T(1))$

$F A=T T(2) / T T(2)$

$F A D=B R *(1,-F A / A T+F A * * 2)$

$S A=S D+(T A-F A) / F A D$

IF( $S A-S O) 56,67.67$

$56 S A=.5 *(S O+S D)$

GO TO 55

67 IF (SM-SA) 68,57,57

$68 S A=, 5 *(S M+S D)$

GO TO 55

57 IF ( ABSF (SA-SD)-.005) $58,55,55$

58 If (IK) $59,59,60$

$59 E K=B K /(1 .+A M *(B-B R * 2+5,7831 /(R U+S A) * 2)$

60 IFISC-SO) $64,64,65$

$64 I K=10$

$65 I K=I K+1$

IF( IK-10) $63,63,80$

63 IF ( SA-SB ) $61,80,61$

61 IF( ABSF ( SA-SC.)-.005) 80,62,62

62 CALL SEP(DIA,SC,SA, SB,SP,SQ,IK)

GO TO 48

80 RETURN

END $(1,0,0,0,0)$ 
C COYPUTES INTERACTION INTEGRAL FDR FINITE CYLINDERS AS A FUNCTIDN

C OF R=RADIUS/(AXIS-TO-AXIS SEPARATION) AND OF S=RADIUS/HEIGHT $\operatorname{RADF}(U, V)=\operatorname{SQRTF}(1 . / R * 2-(U+V) * * 2)$

GRDF $(U, V)=A T A N F(1, /(S *(R A D F(U, V)-S Q R T F(1,-U * * 2)-S Q R T F(1,-V * * 2))))$ IRADF $(U, V)$

DIMENSION $X(8), H(8)$

$N=8$

$x(1)=.98940093$

$x(2)=.94457502$

$X(3)=.86563120$

$X(4)=.75540441$

$x(5)=.61787624$

$x(6)=.45801678$

$X(7)=.28160355$

$X(B)=.095012510$

$H(1)=.02715246$

$H(2)=.06225352$

$H(3)=.09515851$

$H(4)=.12462897$

$H(5)=.14959599$

$H(6)=.16915652$

$H(7)=.18260342$

$H(8)=.18945061$

IF (S) $1,5.1$

$1 S U M=0$.

DO $4 I=1, N$

DO $4 \mathrm{~J}=1, \mathrm{I}$

If $(I-J) 3,3,2$

2 SUM $=S U M+4 . * H(1) * H(J) *(\operatorname{GRDF}(X(1), X(J))+G R D F(X(1),-X(J)))$ GO TO 4

3 IF $(R-.5) 10,11,10$

10 SUM $=\operatorname{SUM}+2 \cdot * H(J) * 2 *(G R D F(X(J), X(J))+G R D F(X(J),-X(J)))$ 60 TO 4

11 SUM $=\operatorname{SUM}+2 \cdot * H(J) * * 2 *(1.5707963 / \operatorname{RADF}(X(J), X(J)) * \operatorname{GRDF}(X(J),-X(J))$

4 CONTINUE

CLDRCT= .050660591*SUM

GO TO $B$

$58=2 . * R$

$E=1 \cdot-8 * * 2$

IF(E) $6,6,7$

6 CLDRCT=.18169012

GO TO 8

7 C=ATANF (B/SQRTF (E))

CLDRCT $=.31830988 *(C-S I N F(.5 * C) / C O S F(.5 * C))$

6 RETURN

ENO $(1,0,0,0,0)$ 


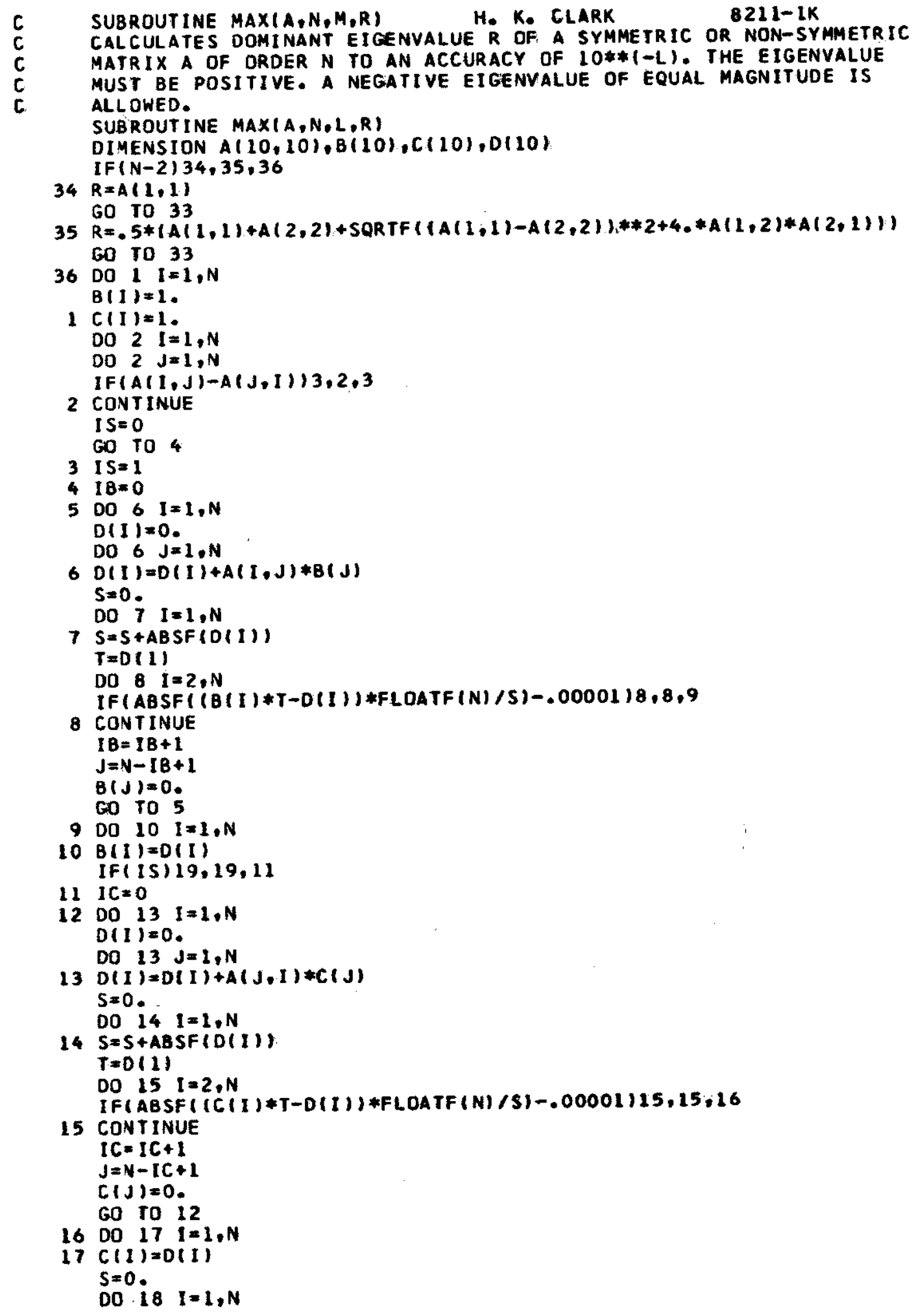




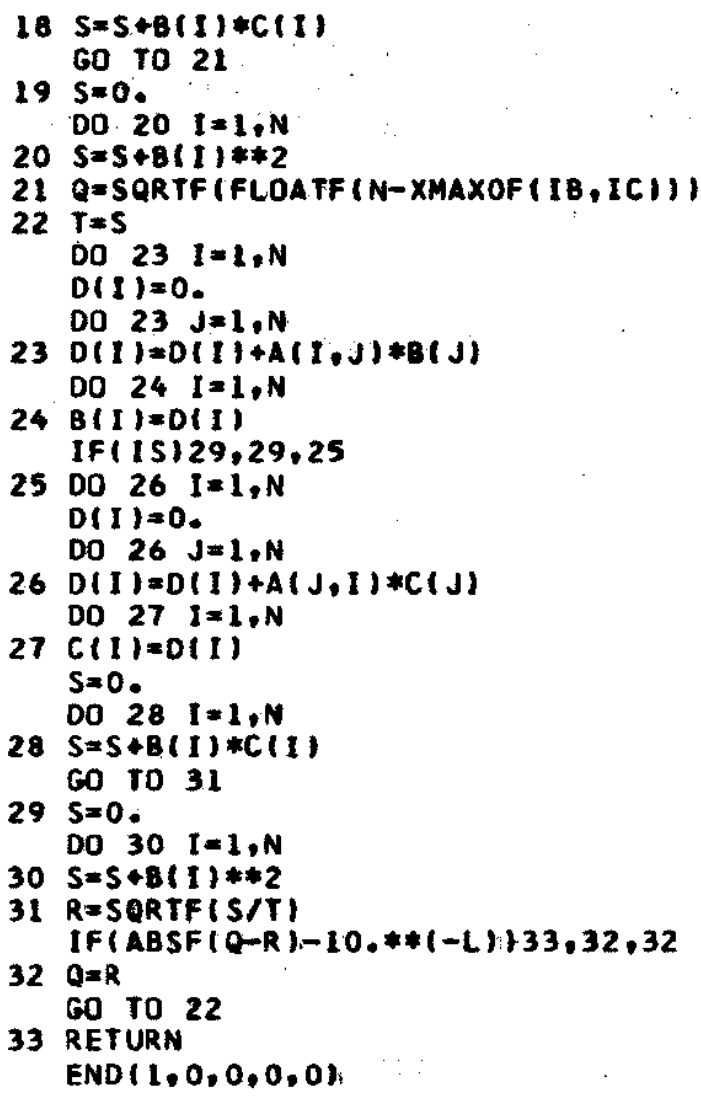


3 CONTINUE

$L=N$

$4=1$

60 To 11

$5 L=1$ $H(L)=11 .-5 U M+H(L) * W D I(L)) / W D I(L)$

$120012 \mathrm{j}=1$, NM

DO $12 K=1, N M$

$12 \times I V(J, K)=0$.

$0013 \mathrm{~J}=1$, NM

DO $13 \mathrm{~K}=1$, NM

DO $13 I=1, L$

IF (WUF $(I, J, K) 13,13,14$

$14 \operatorname{XIV}(J, K)=X I N(J, K)+W U F(I, J, K) * H(I)$

13 CONTINUE If ( AR I $10,30,10$

10 DO $16 \mathrm{~J}=1$, NM $\operatorname{RRU}(j)=0$. OO $15 \mathrm{~K}=1$. NM

$15 \operatorname{RRU}(J)=R \operatorname{RU}(J)+X I N(J, K)$ $\operatorname{RRU}(J)=(1 .-R R \cup(J))$

16 RUR $(J)=R R U(J) * 12.5664 * R U * * 2 / 5 R$ SUM $=0$.

DO $17 \mathrm{~J}=1$, NM 
17 SUM $=S U M+R U R(J) * W S T(J)$

$R R R=1 .-5 U M$

DO $18 \mathrm{~J}=1, \mathrm{NM}$

$18 A(J) \neq R R U(J) * A R * W S T(J) \mu(l \cdot-R R R * A R)$

DO $19 \mathrm{~J}=1, \mathrm{NM}$

DO $19 K=1, N M$

$19 \times I N(J, K)=X I N(J, K)+R U R(J I * A(K)$

30 CALL MAXIXIN,NM, $5, Y)$

I $F(B) 80,80,53$

$53 T A=(1 \cdot+Y) * T T /(1,-Y) *(1 \cdot+T T * T C / T S))$

$42 S D=S A$

$F S=$ SINF (SA*BR)

$F C * C D S F(S A * B R)$

$F T=3.1415927-S A * B R$

$F A=F T /(1,+F T * F C / F S)$

$F A D=B R *(F T * * 2-F S * * 2) /(F S+F T * F C) * 2$

$S A=S D+(T A-F A) / F A D$

IF ( SA-SO ) $43,54,54$

$43 S A=.5 *(S D+S D)$

GO TO 42

54 IF( SM-SA) $55,44,44$

$55 S A=-5 *(S M+S D)$

GO 1042

44 IF (ABSF (SA-SD)-.005) 45.42 .42

45 IF(IK) $46,46,47$

$46 E K=B K /(1++A H * 9.8696044 /(R U+S A) * 2)$

47 IF (SC-SO) 51.51 .52

51 IK $=10$

$52 I K=I K+1$

If $(I K-10) 50,50,80$

50 IF(SA-SB $) 48,80,48$

48 IF (ABSF $(S A-S C)-.005) 80,49,49$

49 CALL SEP(DIA,SC,SA, SB,SP,SQ,IK)

60 TO 40

80 RETURN

END $(1,0,0,0,0)$ 
FUNCTION SPHRCT

H. K. CLARK $8211-1 K$

FUNCTION SPHRCTIX)

DIMENSION PL $(5), R F(5), F P(5), F M(5)$

$F Z=.0590$

$F P(1)=.0724$

$F P(2)=.0857$

FP( 3$)=.1034$

$F P(4)=.2254$

$F P(5)=0.1674$

$F M(1)=.0465$

$F M(2)=.0354$

$F M(3)=.0238$

$F M(4)=.0119$

$F M(5)=0$.

RFZ $=6.9444444 E-05$

$R F(1)=5.7870370 E-05$

$R F(2)=3.3068783 E-05$

$R F(3)=1.2400794 E-05$

$R F(4)=2.7557319 E-06$

$R F(5)=2.7557319 E-07$

$P=20 . * x-5$.

DO $1\{1=1,5$-FLOAT $(1) * 2$

$1 \quad P L(I)=P A=0$.

SUM $6 \quad i=1.6$

$P R D D=1$.

DO $3 \mathrm{~J}=2,6$

IF $(J-1) 2,3,2$

2 PRDD $=P R O D \neq P L(J-1)$

3 CONTINUE

IF $(1-1) 4,4,5$

4 SUM $=$ SUM-PROD $* R F Z * F Z$

GO TO 6
SUM $=S U M+R F(I-1) * P R O D * F$
$1-F L O A T F(I-1) * F M(I-1)$

o CONTINUE

SPHRCT $=(1,+$ SUM $* .5 * 11,-\operatorname{SQRTF}(1,-X * 2)$

RETURN

END $(1,0,0,0,0)$ 
APPENDIX B - Cubic Arrays of Spheres

$\begin{array}{lcccccccccccccc}\operatorname{SDU}(I) & 1 & 2 & 3 & 5 & 6 & 9 & 10 & 11 & 13 & 14 & 17 & 18 & 19 & 21 \\ & 22 & 25 & 26 & 27 & 29 & 30 & 33 & 34 & 35 & 37 & 38 & 41 & 42 & 43 \\ & 45 & 46 & 49 & 50 & 51 & 53 & 54 & 57 & 58 & 59 & 61 & 62 & 65 & 66 \\ \text { WDI (I) } & 6 & 12 & 8 & 24 & 24 & 24 & 24 & 24 & 24 & 48 & 48 & 24 & 24 & 48 \\ & 24 & 24 & 72 & 24 & 72 & 48 & 48 & 48 & 48 & 24 & 72 & 96 & 48 & 24 \\ & 48 & 48 & 48 & 72 & 48 & 72 & 72 & 48 & 24 & 72 & 72 & 96 & 96 & 96\end{array}$

$2 \times 2 \times 2$

WST(I) 8

$W U F(I, J, K) \quad 3 \quad 3 \quad 1$ 
$3 \times 3 \times 3$

\begin{tabular}{|c|c|c|c|c|c|c|}
\hline WST (I) & 1 & 6 & 12 & 8 & & \\
\hline \multirow{16}{*}{$\mathrm{WUF}(I, J, K)$} & 0 & 0 & 0 & 0 & 0 & 0 \\
\hline & 1 & 0 & 0 & 0 & 0 & 0 \\
\hline & 0 & 1 & 0 & 0 & 0 & 0 \\
\hline & 0 & 0 & 1 & 0 & 0 & 0 \\
\hline & 6 & 0 & 0 & 0 & 0 & 0 \\
\hline & 0 & 4 & 0 & 0 & 0 & 0 \\
\hline & 2 & 0 & 2 & 2 & 0 & 0 \\
\hline & 0 & 3 & 0 & 0 & 3 & 0 \\
\hline & 0 & 12 & 0 & 0 & 0 & 0 \\
\hline & 4 & 0 & 4 & 4 & 0 & 0 \\
\hline & 0 & 4 & 0 & 0 & 4 & 0 \\
\hline & 3 & 0 & 0 & 6 & 0 & 3 \\
\hline & 0 & 0 & 8 & 0 & 0 & 0 \\
\hline & 0 & 4 & 0 & 0 & 4 & 0 \\
\hline & 2 & 0 & 0 & 4 & 0 & 2 \\
\hline & 0 & 0 & 0 & 0 & 0 & 0 \\
\hline
\end{tabular}




$$
4 \times 4 \times 4
$$

\begin{tabular}{|c|c|c|c|c|c|c|c|c|c|c|c|c|c|c|c|}
\hline WST $(I)$ & 8 & 24 & 24 & 8 & & & & & 0 & 0 & 0 & 0 & 0 & 0 & 0 \\
\hline \multirow{11}{*}{$\mathrm{WUF}(I, J, K)$} & 1 & 2 & 1 & 2 & 2 & 1 & 0 & 0 & 0 & 0 & 0 & 0 & 0 & 0 & 0 \\
\hline & 0 & 1 & 1 & 0 & 3 & 3 & 0 & 0 & 0 & 0 & 0 & 0 & 0 & 0 & 0 \\
\hline & 0 & 0 & 1 & 6 & 3 & 0 & 0 & 0 & 0 & 0 & 0 & 0 & 0 & 0 & 0 \\
\hline & 3 & 6 & 3 & & 4 & 2 & 2 & 1 & 0 & 0 & 0 & 0 & 0 & 0 & 0 \\
\hline & 2 & 3 & 2 & 4 & 4 & & & 2 & 2 & 2 & 0 & 0. & 0 & 0 & 0 \\
\hline & 2 & 2 & $\cdot 1$ & 2 & 3 & 3. & 2 & & & 6 & & $0^{\prime}$ & 0 & 0 & 0 \\
\hline & 0 & 3 & 0 & 6 & 0 & 0 & 0 & 3 & 0 & 0 & 3 & & & & \\
\hline & 0 & 3 & 3 & 6 & 6 & 3 & 0 & 0 & 0 & 0 & 0 & 0 & 0 & 0 & 0 \\
\hline & 2 & 2 & 1 & 2 & 3 & 3 & 2 & 2 & 2 & 2 & 0 & 0 & 0 & 0 & 0 \\
\hline & 1 & 2 & 0 & 4 & 0 & 0 & 2 & 2 & 0 & 4 & 2 & 0 & 1 & 0 & 0 \\
\hline & 3 & 0 & 0 & 0 & 0 & 0 & 6 & 0 & 6 & 0 & 0 & 0 & 3 & 0 & 3 \\
\hline & 0 & 0 & 1 & 0 & 3 & 3 & 0 & 0 & 0 & 0 & 0 & 0 & 0 & 0 & 0 \\
\hline , & 0 & 1 & 0 & 2 & 0 & 0 & 0 & 1 & 0 & 2 & 1 & 0 & 0 & 0 & 0 \\
\hline . & 1 & 0 & 0 & 0 & 0 & 0 & 2 & 0 & 2 & 0 & 0 & 0 & 1 & 0 & 1 \\
\hline & 0 & 0 & 0 & 0 & 0 & 0 & 0 & 0 & 0 & 0 & 0 & 0 & 0 & 0 & 0 \\
\hline
\end{tabular}


$5 \times 5 \times 5$

$\begin{array}{lllllllllll}\text { WSTI(I) } & 1 & 6 & 12 & 8 & 6 & 24 & 24 & 12 & 24 & 8\end{array}$

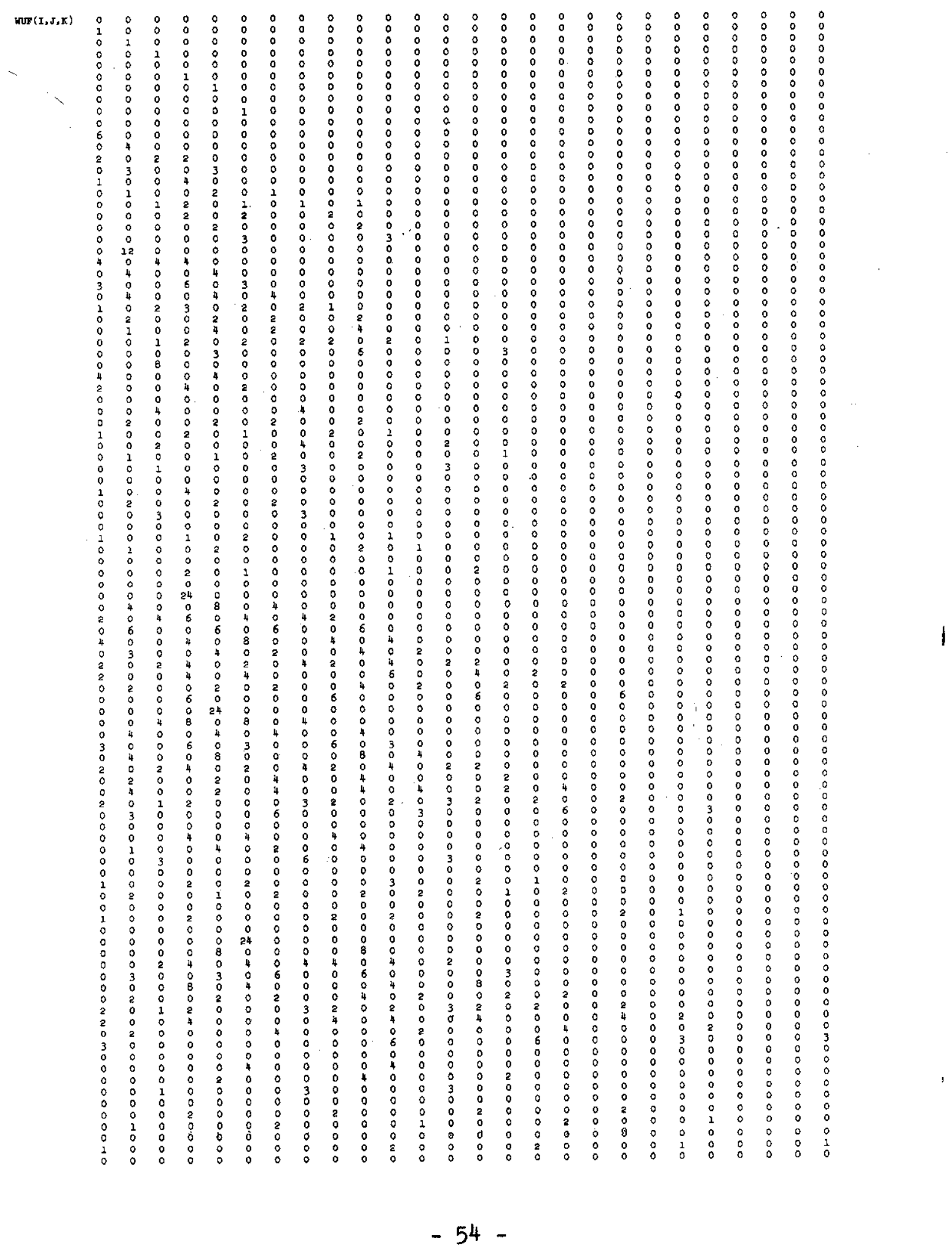




\section{APPENDIX C - Square Arrays of Cylinders}

$\begin{array}{lrrrrrrrrrrrrrr}\operatorname{SDU}(I) & 1 & 2 & 5 & 10 & 13 & 17 & 25 & 26 & 29 & 34 & 37 & 41 & 50 & 53 \\ & 58 & 61 & 65 & 73 & 74 & 82 & 85 & & & & & & & \\ \operatorname{WDI}(I) & 4 & 4 & 8 & 8 & 8 & 8 & 8 & 8 & 8 & 8 & 8 & 8 & 8 & 8 \\ & 8 & 8 & 16 & 8 & 8 & 8 & 16 & & & & & & & \end{array}$

$1 \times 2$

$\begin{array}{ll}W S T(I) & 2 \\ W U F(I, J, K) & I\end{array}$

$1 \times 3$

$\begin{array}{lll}W S T(I) & 1 & 2 \\ W U F(I, J, K) & 0 & \\ & 1 \\ & 2 \\ & 0\end{array}$

$1 \times 4$

$\begin{array}{lll}W S T(I) & 2 & 2 \\ W U F(I, J, K) & 1 \\ & 1 \\ 1 \\ 0\end{array}$


$1 \times 5$

\begin{tabular}{|c|c|c|}
\hline WST(I) & 1 & 2 \\
\hline $\operatorname{WUF}(I, J, K)$ & 0 & \\
\hline & 1 & \\
\hline & 0 & \\
\hline & 2 & \\
\hline & 0 & \\
\hline & 1 & \\
\hline & 0 & \\
\hline & $I$ & \\
\hline & 0 & \\
\hline
\end{tabular}

$1 \times 6$

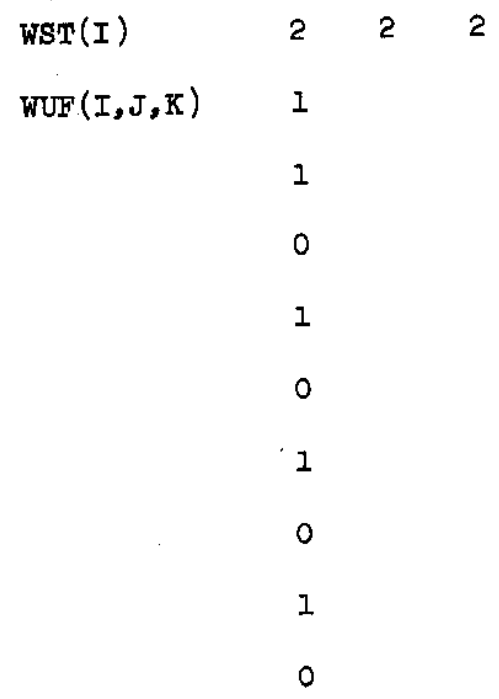

$2 \times 2$

\begin{tabular}{|c|c|}
\hline WST (I) & 4 \\
\hline WUF $(I, J, K)$ & 2 \\
\hline
\end{tabular}


$3 \times 3$

$\begin{array}{llll}W S T(I) & 1 & 4 & 4 \\ W U F(I, J, K) & 0 & 0 & 0 \\ 1 & 0 & 0 \\ 0 & 1 & 0 \\ 4 & 0 & 0 \\ 0 & 2 & 0 \\ 2 & 0 & 2 \\ 0 & 4 & 0 \\ 2 & 0 & 2 \\ 0 & 0 & 0\end{array}$

$4 \times 4$

$\begin{array}{llllll}W S T(I) & 4 & 8 & 4 & & \\ W U F(I, J, K) & 2 & 1 & 0 & 0 & 0 \\ & 1 & 1 & 1 & 0 & 0 \\ & 0 & 1 & 2 & 0 & 0 \\ 2 & 2 & 2 & 0 & 0 \\ 1 & 1 & 2 & 1 & 0 \\ 2 & 0 & 0 & 2 & 2 \\ & 0 & 1 & 2 & 0 & 0 \\ 1 & 0 & 0 & 1 & 1 \\ & 0 & 0 & 0 & 0 & 0\end{array}$

$-57-$ 


\begin{tabular}{|c|c|c|c|c|c|c|c|}
\hline \multirow{4}{*}{$\begin{array}{l}\text { WST (I) } \\
W U F(I, J, K)\end{array}$} & \multirow{2}{*}{1} & & \multicolumn{2}{|c|}{$5 \times 5$} \\
\hline & & 4 & 4 & 4 & 8 & 4 & \\
\hline & 0 & 0 & 0 & 0 & 0 & 0 & 0 \\
\hline & 1 & 0 & 0 & 0 & 0 & 0 & 0 \\
\hline & 0 & 1 & 0 & 0 & 0 & 0 & 0 \\
\hline & 0 & 0 & 0 & 0 & 0 & 0 & 0 \\
\hline & 0 & 0 & 1 & 0 & 0 & 0 & 0 \\
\hline & 0 & 0 & 0 & 0 & 0 & 0 & 0 \\
\hline & 4 & 0 & 0 & 0 & 0 & 0 & 0 \\
\hline & 0 & 2 & 0 & 0 & 0 & 0 & 0 \\
\hline & 2 & 0 & 2 & 0 & 0 & 0 & 0 \\
\hline & $I$ & 0 & 2 & 0 & 0 & 0 & 0 \\
\hline & 0 & 1 & 0 & 1 & 0 & 0 & 0 \\
\hline & 0 & 0 & 2 & 0 & 2 & 0 & 0 \\
\hline & 0 & 4 & 0 & 0 & 0 & 0 & 0 \\
\hline & 2 & 0 & 2 & 0 & 0 & 0. & 0 \\
\hline & 0 & 0 & 0 & 0 & 0 & 0 & 0 \\
\hline & 0 & 2 & o & 2 & 0 & 0 & 0 \\
\hline & 1 & 0 & I & 0 & 1 & 0 & 0 \\
\hline & 0 & 2 & 0 & 2 & 0 & 0 & 0 \\
\hline & 0 & 0 & 0 & 0 & 0 & 0 & 0 \\
\hline & 1 & 0 & 2 & 0 & 0 & 0 & 0 \\
\hline & 0 & 2 & 0 & 2 & 0 & 0 & 0 \\
\hline & 0 & 0 & 0 & 0 & 0 & 0 & 0 \\
\hline & 1 & 0 & 1 & 0 & 2 & 1 & 0 \\
\hline & 0 & 0 & 0 & 0 & 0 & 0 & 0 \\
\hline & 0 & 0 & 8 & 0 & 0 & 0 & 0 \\
\hline & 0 & 2 & 0 & 2 & 0 & 0 & 0 \\
\hline & 2 & 0 & 2 & 0 & 2 & 0 & 0 \\
\hline & 2 & 0 & 2 & 0 & 2 & 2 & 0 \\
\hline & 0 & 1 & 0 & 2 & 0 & 0 & 0 \\
\hline & 2 & 0 & 0 & 0 & 0 & 2 & 2 \\
\hline & 0 & 0 & 0 & 0 & 0 & 0 & 0 \\
\hline & 0 & 0 & 2 & 0 & 2 & 0 & 0 \\
\hline & 0 & 1 & 0 & 2 & 0 & 0 & 0 \\
\hline & 0 & 0 & 0 & 0 & 0 & 0 & 0 \\
\hline & 1 & 0 & 0 & 0 & 0 & 1 & 1 \\
\hline & 0 & 0 & 0 & 0 & 0 & 0 & 0 \\
\hline
\end{tabular}

$-58-$ 


$$
6 \times 6
$$

WST (I)

WUF $(I, J, K)$ $\begin{array}{llllll}4 & 8 & 4 & 8 & 8 & 4\end{array}$

$\begin{array}{llllllllllll}2 & 1 & 0 & 0 & 0 & 0 & 0 & 0 & 0 & 0 & 0 & 0 \\ 1 & 2 & 1 & 0 & 0 & 0 & 0 & 0 & 0 & 0 & 0 & 0 \\ 0 & 1 & 0 & 0 & 0 & 0 & 0 & 0 & 0 & 0 & 0 & 0\end{array}$

$\begin{array}{llllllllllll}0 & 0 & 1 & 1 & 0 & 0 & 0 & 0 & 0 & 0 & 0 & 0\end{array}$

$\begin{array}{llllllllllll}0 & 0 & 1 & 1 & 1 & 0 & 0 & 0 & 0 & 0 & 0 & 0\end{array}$

$\begin{array}{llllllllllll}0 & 0 & 0 & 0 & 2 & 0 & 0 & 0 & 0 & 0 & 0 & 0\end{array}$

$\begin{array}{llllllllllll}2 & 2 & 2 & 0 & 0 & 0 & 0 & 0 & 0 & 0 & 0 & 0\end{array}$

$\begin{array}{llllllllllll}1 & 1 & 2 & 1 & 0 & 0 & 0 & 0 & 0 & 0 & 0 & 0\end{array}$

$\begin{array}{llllllllllll}2 & 0 & 0 & 2 & 2 & 0 & 0 & 0 & 0 & 0 & 0 & 0\end{array}$

$\begin{array}{llllllllllll}1 & 1 & 1 & 1 & 1 & 1 & 0 & 0 & 0 & 0 & 0 & 0\end{array}$

$\begin{array}{llllllllllll}0 & 1 & 1 & 0 & 1 & 1 & 0 & 0 & 0 & 0 & 0 & 0\end{array}$

$\begin{array}{llllllllllll}0 & 0 & 2 & 2 & 0 & 0 & 2 & 0 & 0 & 0 & 0 & 0\end{array}$

$\begin{array}{llllllllllll}0 & 1 & 2 & 0 & 0 & 0 & 0 & 0 & 0 & 0 & 0 & 0\end{array}$

$\begin{array}{llllllllllll}1 & 0 & 0 & 1 & 1 & 0 & 0 & 0 & 0 & 0 & 0 & 0\end{array}$

$\begin{array}{llllllllllll}0 & 0 & 0 & 0 & 0 & 0 & 0 & 0 & 0 & 0 & 0 & 0\end{array}$

$\begin{array}{llllllllllll}0 & 1 & 1 & 0 & 0 & 1 & 0 & 0 & 0 & 0 & 0 & 0\end{array}$

$\begin{array}{llllllllllll}1 & 0 & 0 & 1 & 0 & 0 & 1 & 0 & 0 & 0 & 0 & 0\end{array}$

$\begin{array}{llllllllllll}0 & 1 & 0 & 0 & 0 & 2 & 0 & 0 & 0 & 0 & 0 & 0\end{array}$

$\begin{array}{llllllllllll}0 & 0 & 2 & 2 & 0 & 0 & 0 & 0 & 0 & 0 & 0 & 0\end{array}$

$\begin{array}{llllllllllll}1 & 1 & 1 & 1 & 1 & 1 & 0 & 0 & 0 & 0 & 0 & 0\end{array}$

$\begin{array}{llllllllllll}0 & 2 & 2 & 0 & 0 & 2 & 0 & 0 & 0 & 0 & 0 & 0\end{array}$

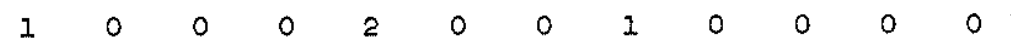

$\begin{array}{llllllllllll}1 & 0 & 1 & 1 & 0 & 0 & 1 & 1 & 1 & 0 & 0 & 0\end{array}$

$\begin{array}{llllllllllll}0 & 0 & 0 & 0 & 0 & 0 & 0 & 0 & 2 & 2 & 0 & 0\end{array}$

$\begin{array}{llllllllllll}0 & 0 & 2 & 2 & 2 & 0 & 0 & 0 & 0 & 0 & 0 & 0\end{array}$

$\begin{array}{llllllllllll}0 & 1 & 1 & 0 & 1 & 1 & 0 & 0 & 0 & 0 & 0 & 0\end{array}$

$\begin{array}{llllllllllll}2 & 0 & 0 & 2 & 0 & 0 & 2 & 0 & 0 & 0 & 0 & 0\end{array}$

$\begin{array}{llllllllllll}1 & 0 & 1 & 1 & 0 & 0 & 1 & 1 & 1 & 0 & 0 & 0\end{array}$

$\begin{array}{llllllllllll}0 & 1 & 0 & 0 & 0 & 2 & 0 & 0 & 0 & 1 & 0 & 0\end{array}$

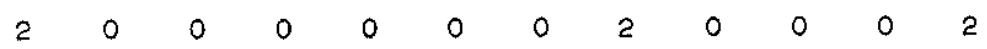

$\begin{array}{llllllllllll}0 & 0 & 0 & 0 & 2 & 0 & 0 & 0 & 0 & 0 & 0 & 0\end{array}$

$\begin{array}{llllllllllll}0 & 0 & 1 & 1 & 0 & 0 & 1 & 0 & 0 & 0 & 0 & 0\end{array}$

$\begin{array}{llllllllllll}0 & 1 & 0 & 0 & 0 & 2 & 0 & 0 & 0 & 0 & 0 & 0\end{array}$

$\begin{array}{llllllllllll}0 & 0 & 0 & 0 & 0 & 0 & 0 & 0 & 1 & 1 & 0 & 0\end{array}$

$\begin{array}{llllllllllll}1 & 0 & 0 & 0 & 0 & 0 & 0 & 1 & 0 & 0 & 0 & 1\end{array}$

$\begin{array}{llllllllllll}1 & 0 & 0 & 0 & 0 & 0 & 0 & 0 & 0 & 0 & 0 & 0\end{array}$ 
APPENDIX D - Triangular Arrays of Cylinders

$\begin{array}{lll}\operatorname{SDU}(I) & 1 & 3 \\ \operatorname{WDI}(I) & 6 & 6 \\ & & 3 \\ \operatorname{WST}(I) & 3 & \\ \operatorname{WUF}(I, J, K) & 2 & \\ & & \\ \operatorname{WST}(I) & 1 & 6 \\ \operatorname{WUF}(I, J, K) & 0 & 0 \\ & 1 & 0 \\ & 6 & 0 \\ & 2 & 2\end{array}$

$\begin{array}{lllll}\text { WST }(I) & 1 & 6 & 6 & 6 \\ \text { WUF }(I, J, K) & 0 & 0 & 0 & 0 \\ & 1 & 0 & 0 & 0 \\ & 0 & 1 & 0 & 0 \\ & 0 & 0 & 0 & 0 \\ & 6 & 0 & 0 & 0 \\ & 2 & 2 & 0 & 0 \\ & 2 & 0 & 2 & 0 \\ & 1 & 2 & 2 & 0 \\ & 0 & 6 & 0 & 0 \\ & 2 & 0 & 2 & 0 \\ & 0 & 2 & 0 & 0 \\ & 2 & 0 & 2 & 2 \\ & 0 & 0 & 0 & 0 \\ & 1 & 2 & 2 & 0 \\ & 2 & 0 & 2 & 2 \\ & 0 & 0 & 0 & 0\end{array}$




\section{REFERENCES}

1. H. K. Clark. "Interaction of Fissionable Units." Nucl. Sci. Eng. 15, 20-28 (1963).

2. H. K. Clark. Comparison of a Simple Treatment of Critical Arrays of Fissionable Units with Experiments. USAEC Report DP-868, E. I. du Pont de Nemours and Co., Savannah River Laboratory, Aiken, S. C. (1964).

3. H. K. Clark. "Application of a Simple, Practical Method for Computing Interaction to Arrays Found Experimentally to be Critical." Nucl. Sci. Eng. 20, 307-313 (1964).

4. H. C. Paxton, J. T. Thomas, Dixon Callihan, and E. B. Johnson. Critical Dimensions of Systems Containing $\mathrm{U}^{235}, \mathrm{Pu}^{238}$, and U233. USAEC Report TID-7028, Ios Alamos Scientific Lab., $\bar{N}$. Mex. and Oak Ridge National Lab., Tenn. (1964).

5. J. K. Fox and L. W. Gilley. "Critical Parameters of Aqueous Solutions of $U^{235}$. Applled Nuclear Physics Division, Annual Progress Report for Period Ending September 1, 1957. USAEC Report ORNI-2389, Oak Ridge National Laboratory, Tenn., pp 71-83 (1957).

6. J. K. Fox and L. W. Gilley. Preliminary Report of Critical Experiments in Slab Geometry. USAEC Report ORNL-CF-56-7-148, Oak Ridge National Laboratory, Tenn. (1956) (declassified April 1, 1957).

7. L. W. Gilley, D. F. Cronin, J. K. Fox, and J. T. Thomas. "Critical Arrays of Neutron Interacting Units." Neutron Physics Division Annual Progress Report for Period Ending September 1, 1961. USAEC Report ORNL-3193, Oak Ridge National Laboratory, Tenn., pp 159-167 (1961).

8. E. B. Johnson and D. F. Cronin. "Critical Dimensions of Aqueous $\mathrm{UO}_{2} \mathrm{~F}_{2}$ Solutions Containing 4.9\% $235 \mathrm{U}$-Enriched Uranium." Neutron Physics Division, Annual Progress Report for Period Ending August 1, 1964. USAEC Report ORNL-3714, Oak Ridge National Laboratory, Tenn., pp 31-33 (1964).

9. I. Carlvik and B. Pershagen. The Dancoff Correction in Varlous Geometries. Aktiebolaget Atomenerg1, Stockholm. Report AE-16 (1959). 
Description of Material

No. DP-1031

Date: $6 / 16 / 66$

Title: Interaction of Fissile Units. A Computer Code - INTERACT

Author: H. K. Clark

Type of Material

Classified DP Report

$\square \quad$ Classified Paper

Unclassified DP Report

$x$ Unclassifled Paper

$\square$

Letter

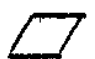

Technical Content

Approved by

$\angle \mathrm{s} / \mathrm{P}$. I. Roggenkamp

Date: $6 / 1 / 66$

Classification

Approved by

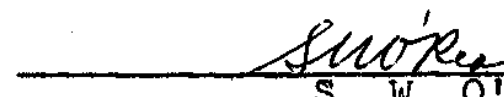

S. W. O'Rear

Date: $6 / 16 / 66$

Authority:

Topics 4 and $5 \cdot 2 \cdot 3$ CG-UF-2

Topics 701 and 702.2 SROO Classification Guide

Category if DP Report

Approved by

Suopers S. W. O'Rear

Date

\section{$1 / 6 / 66$}

Final Du Pont Release

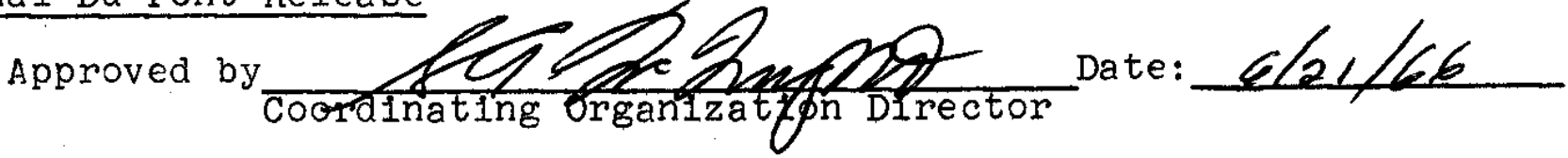

Released by

R. G. Eraley: $C \cdot{ }^{9} 6$ 